\title{
الإنهيار السياسي لأسرة أور الثالثة \\ ونهاية السيادة السومرية
}

د. إسلام مصطفى محمد عبد الله (*)

الملخص:

تعد هذه المرحلة آخر عهد بـلاد الرافدين بحكم سومري خالص، ورغم تتاول

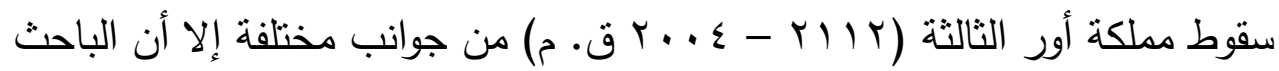

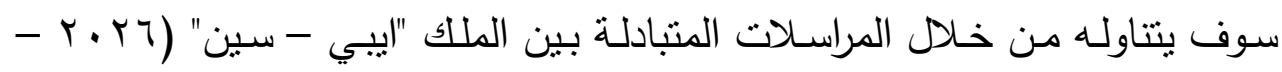

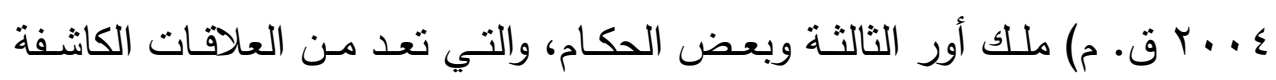

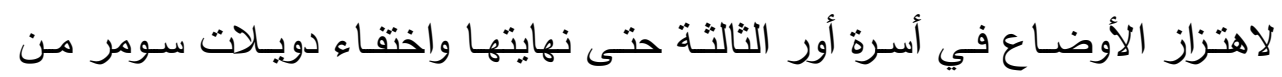

$$
\text { المشهد السياسي. }
$$

ونجد في هذه الرسائل الأسباب المباشرة التي أدت إلى سقوط أسرة أور الثالثة،

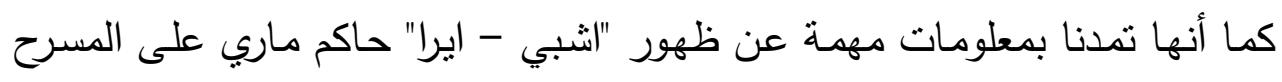

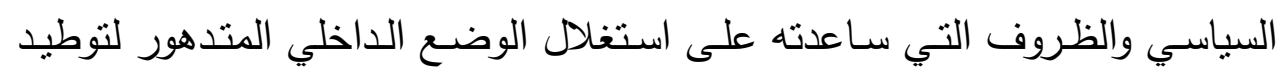

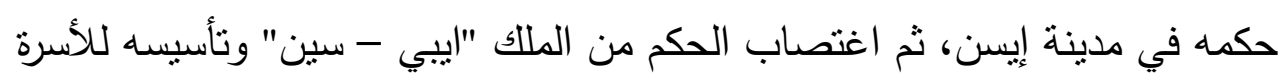

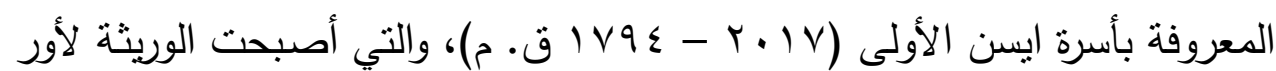

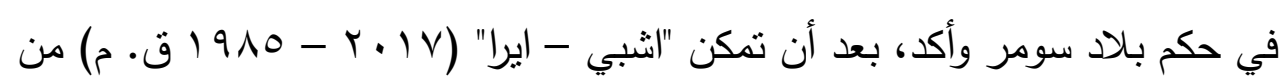

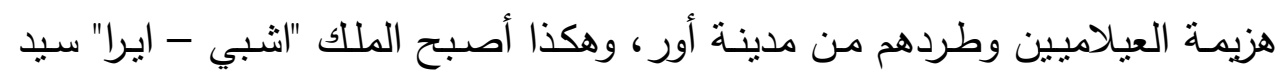
وسط وجنوب بلاد الرافدين دون منازع.

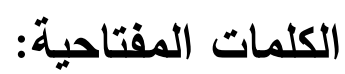

الرسائل ، ايبي - سين ، أسرة أور الثالثة ، اثبي - ايرا ، ايسن ، الأموريون

(*) مدرس تاريخ وحضارة مصر والثرق الأدنى القديم - قسم التاريخ - كلية الآداب - جامعة dr.eslamalexu@gmail.com الإسكندرية. 


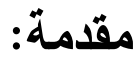

دائمـاً مـا تتحكم في إنهيـار الكيانـات السياسبة العديد مـن العوامل الداخليـة والخارجية، منها الجانب الاقتصادي والسياسي والعسكري، وعلى الرغم مما شهـته

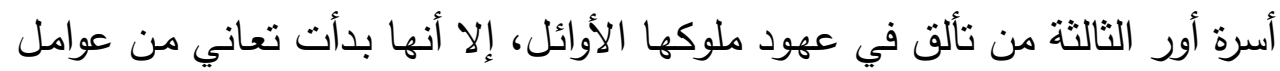

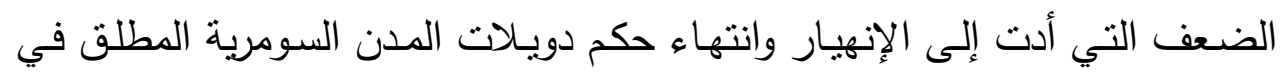

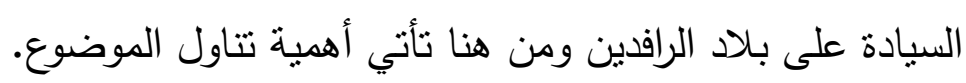

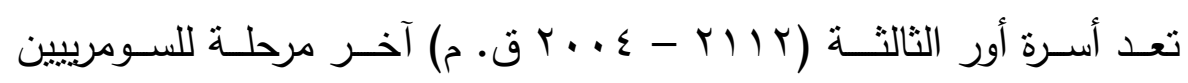

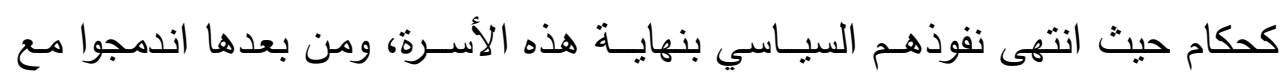
الساميين ولكن ظل تأثنرهم الحضـاري مستمراً وتمثل ذلك في لغنتهم وآدابهم التي لتي

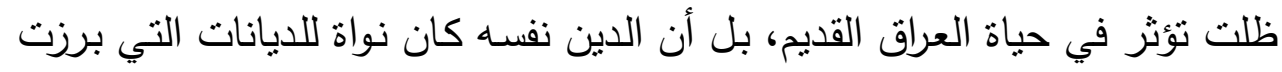

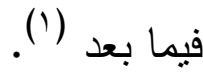

دام حكم أسرة أور الثالثة (خريطة رقم ())، زهاء القرن الواحد لم تكتف فيه

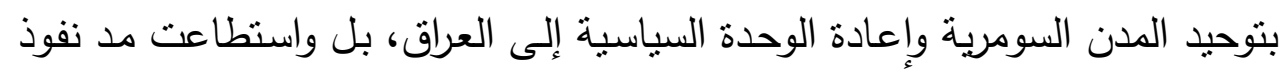

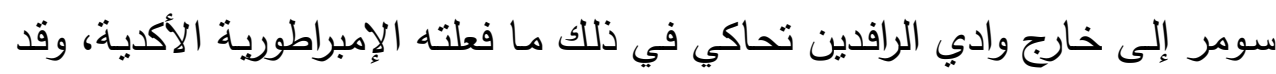

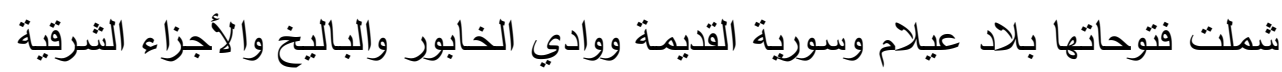
من آسيا الصغرى ومناطق الخليج العربي (r). وقد خضعت ماري(r) أيضاً لنفوذ أسرة أور الثالثة، وقام على حكمها عدد من الحكام التابعين لملوك هذه الأسرة، وقدر لأحد هؤلاء الحكام وهو "اثببي - ايرا"

(1) أحمد أمين سليم: دراسات في تاريخ وحضارة الثرق الأدنى القديم، تاريخ العراق - إيران - الإبهان

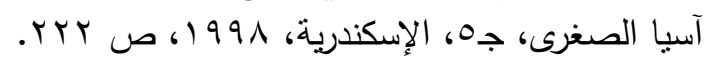

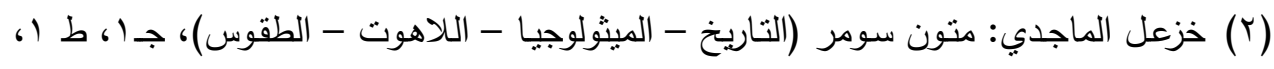

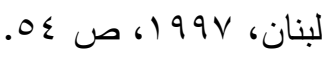

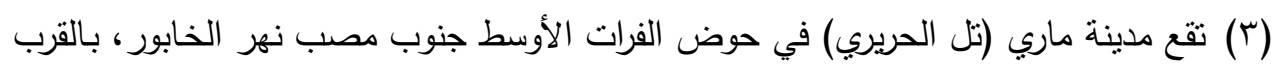
من قرية (البوكمال الحالية) في محافظة دير الزئ في الزور ، النظر :

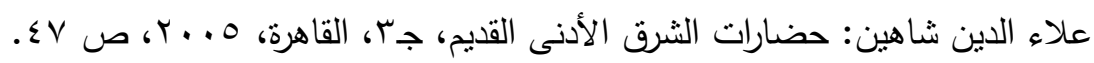


(910 - Y . lV)

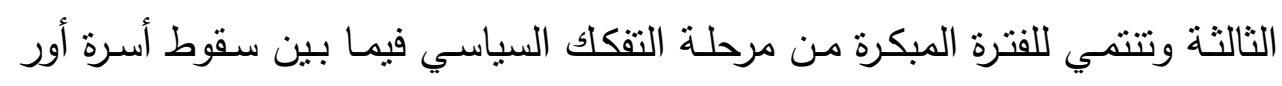

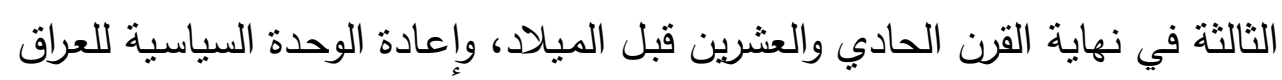

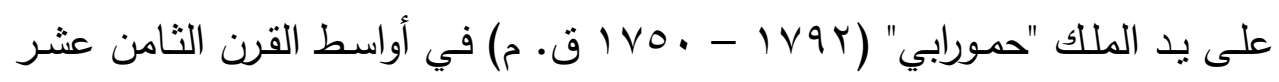
قبل الميلاد (०).

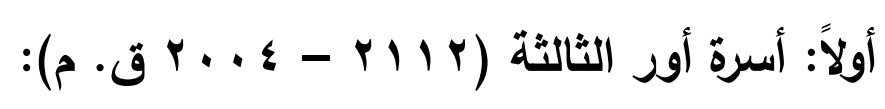

أعنلى عرش أور (T) خمسة ملوك وهم طبقاً لقائمة الملوك السومرية على النحو

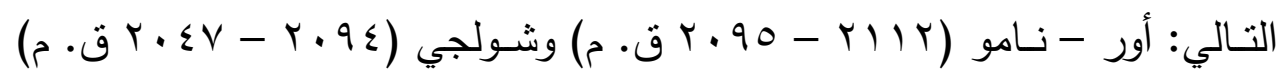

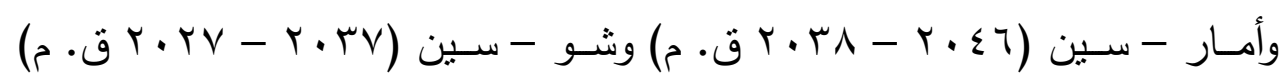

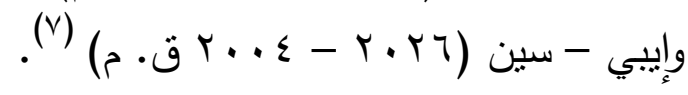

يعد الملك أور - نامو المؤسس الحقيقي لأسرة أور الثالثة، وتمكن من توحيد

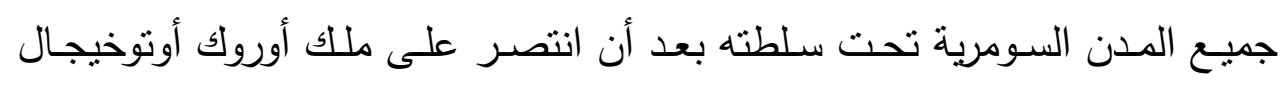

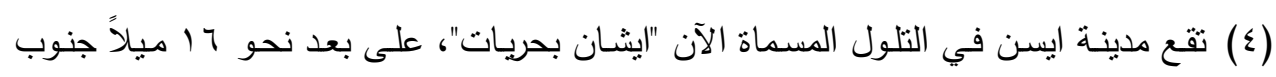
غربي نفر، وفي عام بلو ام أرسلت جامعة ميونيخ الألمانية بعثة أنرية للتنقيب في المدينة، انظر:

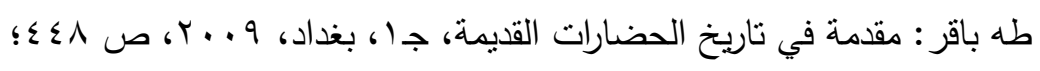
S. Langdon, "The Location of Isin", JRAS, No. 3 (1922), PP. 430 - 431.

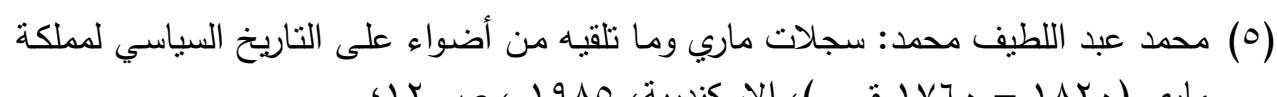

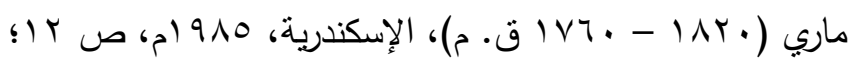

J.R. Kupper, "Un gouvernement Provincial dans le Royaume de Mari", RA, 41 (1947), PP. 152 - 153.

(T) تقع مدينة أور على بعد VI V كم إلى الجنوب الغربي من مدينة الناصرية، وتذكر المصادر

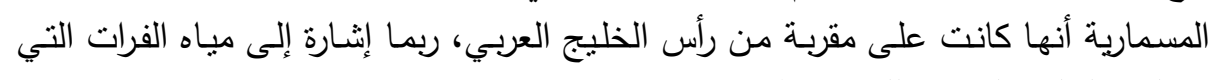

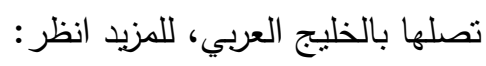

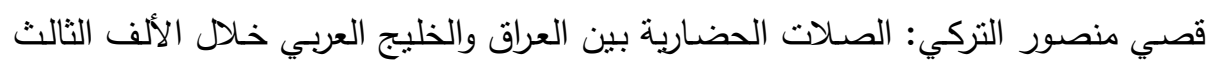

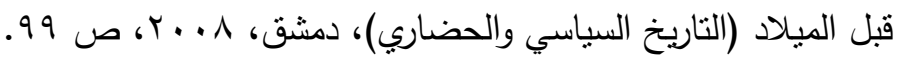

(7) A. Kubrt, The Ancient Near East C.3000 - 330 B.C., Vol. 1, London and New York (1995), P. 63. 


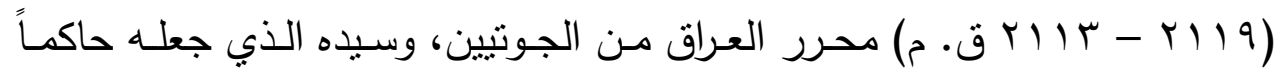

عسكرياً على أور من قبل (^)

ومن النصوص التأريخية المهمة التي دونت في هذه الفترة والفترة التالية لها

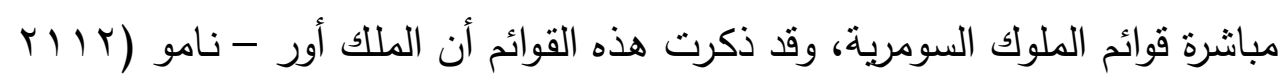

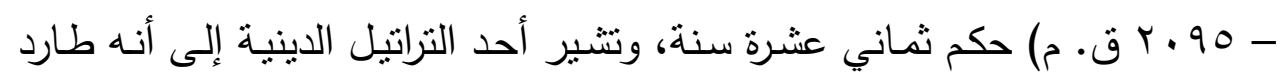
فلول الجوتيين، ويذكر أور - نامو في نصوصه أنه سار من البحر الأسفل (الخليج

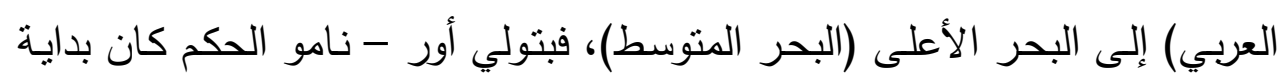

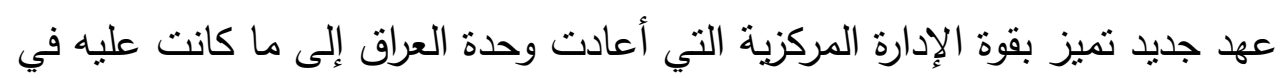

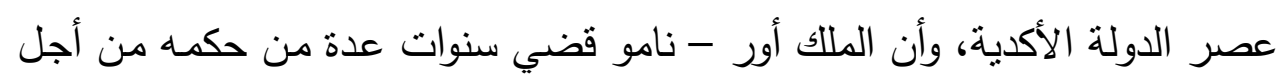

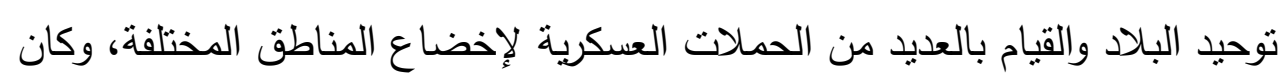

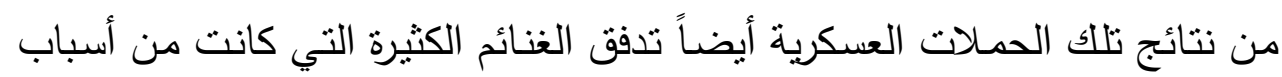

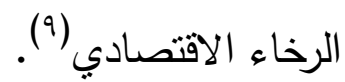

قام الملك أور - نامو في السنوات الأولى من حكمه ببسط سبطرته على كل

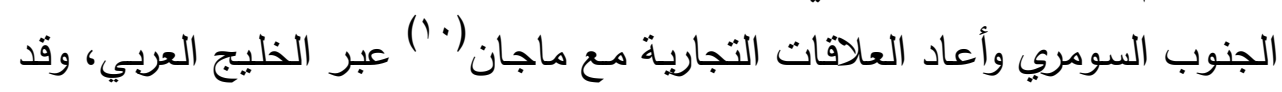
جاء في أحد نصوصه ما يلي:

(^) أحمد رحيم هبو: ناريخ الثرق القديم (بلاد ما بين النهرين)، ط (، صنعاء، 997 (م، ص !)

L. Woolley, Ur of the Chaldees, London (1963), P. 85.

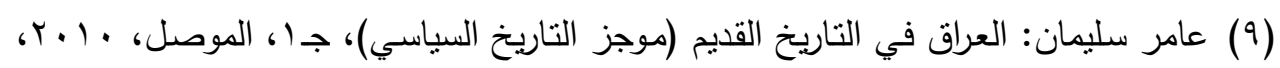
ص .

(• (1) ورد ذكر ماجان (عُمان الحالية) في النصوص السومرية والأكدية في بداية الألف الثالث

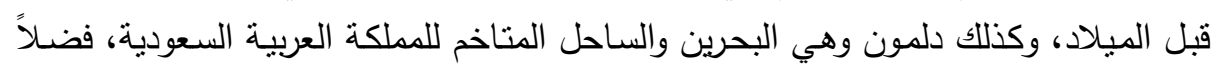

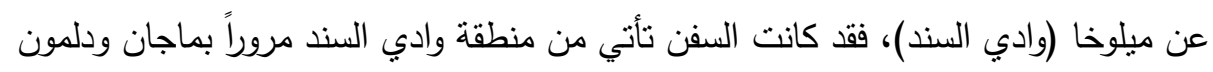
ومنها إلى جنوب العراق، انظر :

D. T. Potts, Ancient Magan, United Arab Emirates (2000), P. 53;

P. Michalowski, "Magan and Meluhha once Again, JCS, Vol. 40, No. 2 (1988). 
"من أجل نانا (إله القمر) بن إنليل، ملكه، جعل أور - نـامو الرجل القوي،

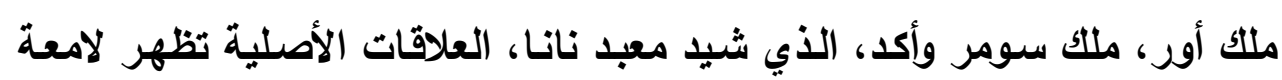

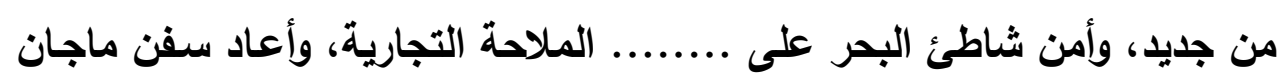
ثانية إلى يده (يد نانا)"(' (').

ومن خـلا هذا النص يتضح أن الملك أور - نـامو أتخذ لقباً سياسياً جديداً

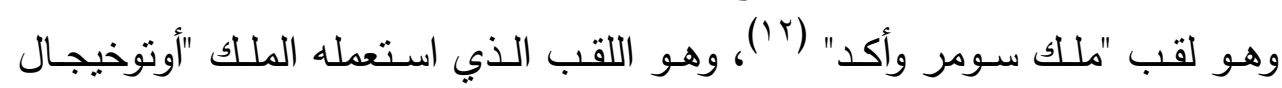

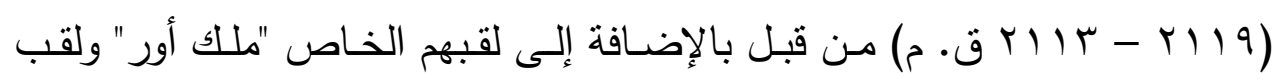
"ملك الجهات الأربع" (r') وإإن ظل هذا اللقب الأخير لقباً تشريفياً أكثر منه لقباً

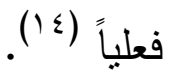

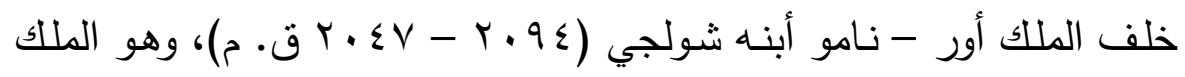
الثاني في أسرة أور الثالثة ولقد بلغت مدة حكمه نحو ثمان وأربعين عاماً، قام خلالها بالعديد من الإصلاحات السياسية والاقتصادية والإدارية (10).

سيطر الملك شولجي على العراق بسهولة ويسر وكذلك بلاد عيلام، وأمتد نفوذ

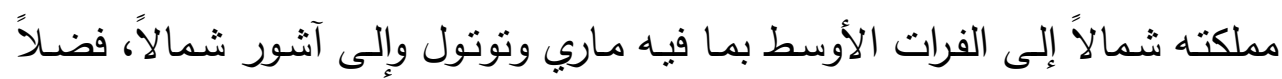
عن جبيل على ساحل البحر المتوسط غرباً، ولم يواجه الملاك شولجي مشكلات ألمات أمنية

(1') عبد مرعي وفيصل عبد الله: تاريخ الوطن العربي القديم (بلاد الرافدين)، جا، ط ع ، دمثق،

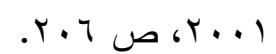

(12) L. Delaporte, Mesopotamia the Babylonian and Assyrian Civilization, Translated by V. G. Child, London and New York (1996), P. 34.

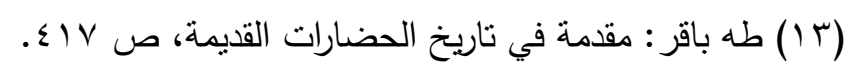

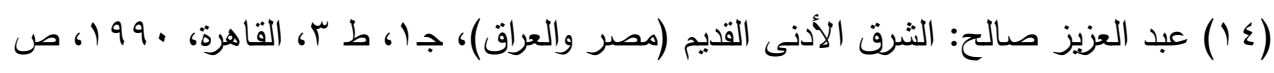
؛ $\{r \mathrm{r}$

H. Crawford, Sumer and the Sumerians, Cambridge (1991), P. 46.

(15) J. Klein, "Shulgi of Ur : King of Aneo Sumerian Empire", CANE, J.M. Sasson, (and Others, eds.) Vol. II, New York (1995), P. 843. 
في مملكته سوى في المنطقة الثمالية والثنمالية الثرقية حول أربيل القريبة من القبائل الجبلية التي أعثادت في الماضي الإغارة على العراق (17').

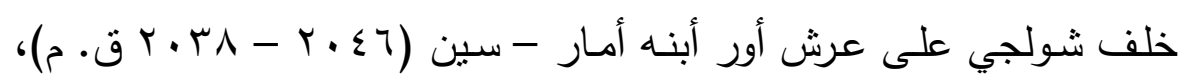

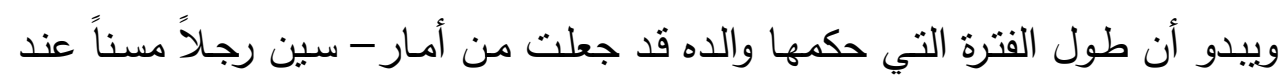

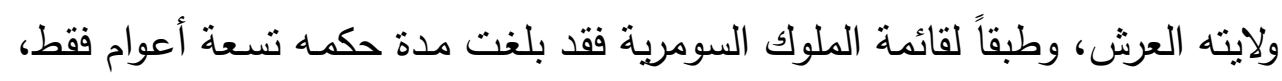

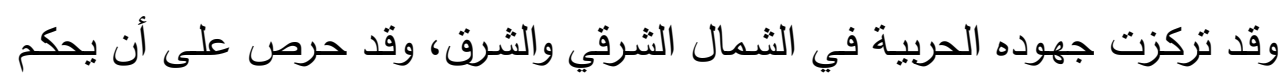

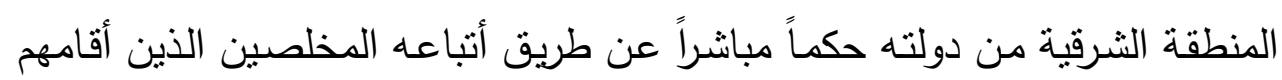

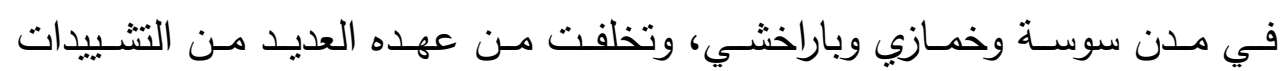

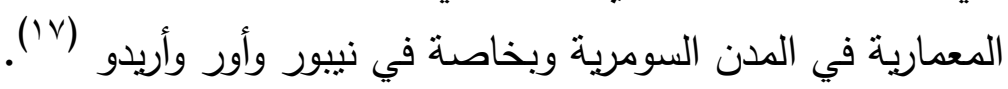

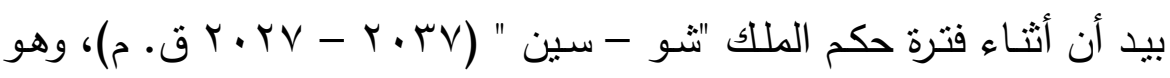

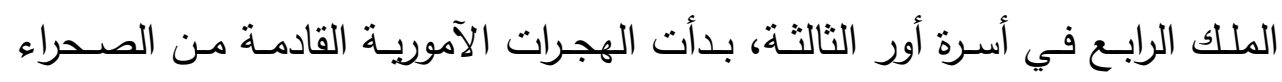

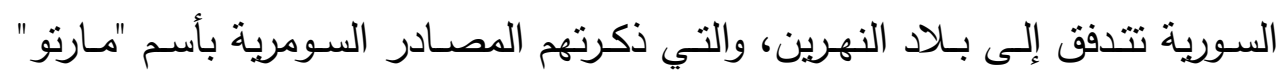

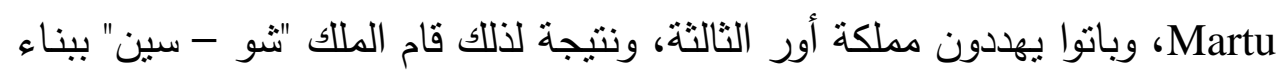

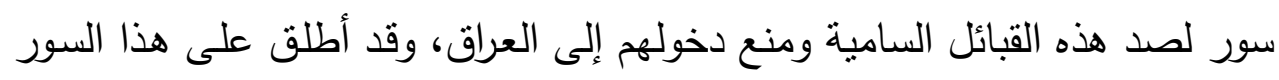

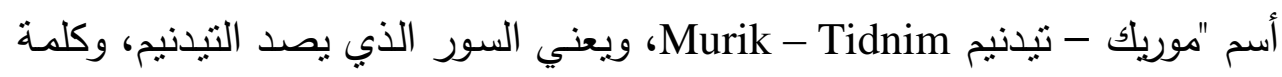

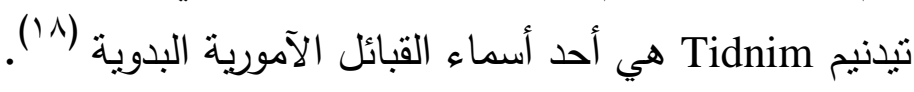

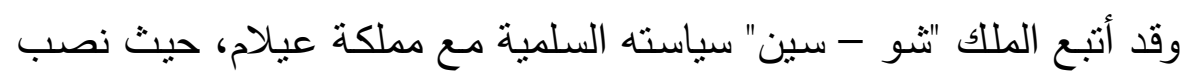
حاكماً تابعاً له في عبلام، وفي العام السادس من حكمه قام بتعيين الملك "كيرناممي"

$$
\begin{aligned}
& \text { (7 (1) محمد حرب فرزات وعيد مرعي: دول وحضارات في الثشرق العربي القديم، ط ك، دمثق، }
\end{aligned}
$$

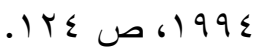

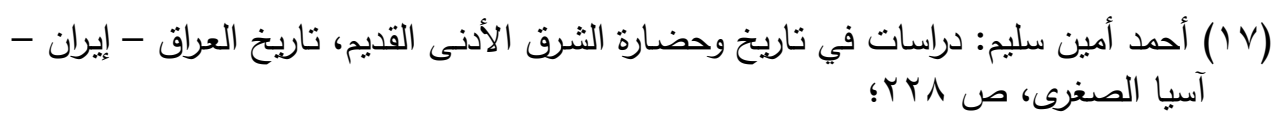

C. J. Gadd, "Babylonia C. 2120 - 1800 B.C", CAH, Vol.1, Part 2A, Cambridge (1971), PP. 607 - 608.

(18) J. Oates, Babylon, Thames and Hudson, London (1979), P. 49;

I. J. Gelb, "The Early History of the West Semitic Peoples, JCS, 15 (1961). 
على مدينة سيماش (9 (') لأول مرة منذ سقوط مملكة أوان (·r) وقد وصل مندوب "كيرناممي" إلى أور وتسلم الكثير من الخراف كأرزاق له، وفي العام الثاني من حكم

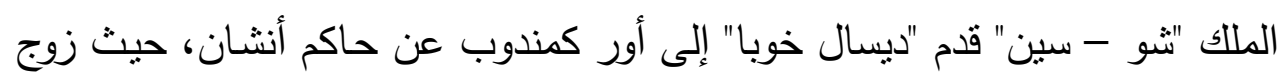

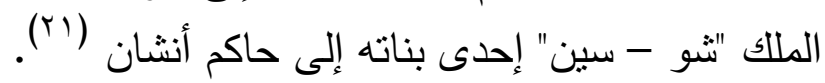

وقد أضطر الملك "شو - سين" كذلك أن يوجه قواته العسكرية إلى الجهات الثرقية والثمالية الثرقية لوقف تحركات القبائل الجبلية حتى يتفرغ إلى الغرب حيث

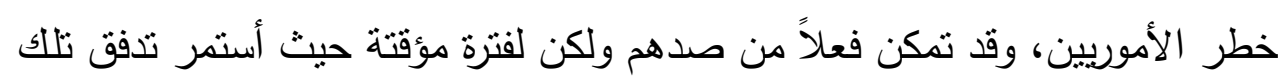
القبائل وزاد ضـطها على حدود مملكة أور الثالثة الغربيـة في عهد الملك "إيبي سين" (r) (r) ( )

أضحت الأوضـاع على الحدود الغربيـة من مملكة أور الثالثة تتذر بـالخطر ، وذلك نتيجة تلك التحركات السامية والتي كانت من الأسباب التي أدت إلى نهايـة

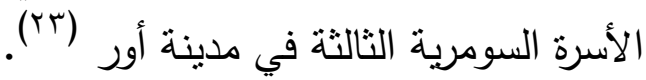

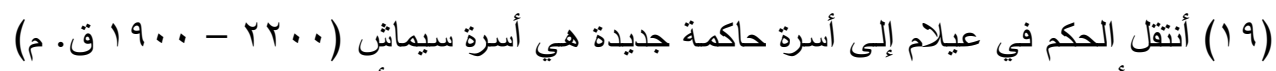

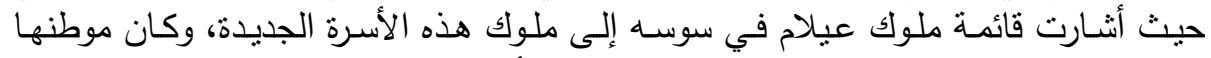
الرئيسي في جبال لورستان إلى الثمال من سوسيانا، أنظر :

W. Hinz, "Persia C. 2400 - 1800 B.C", CAH, Vol. I, Part 2, London and New York (1971), P. 654.

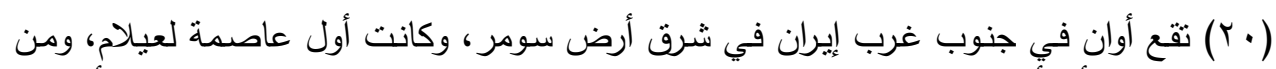

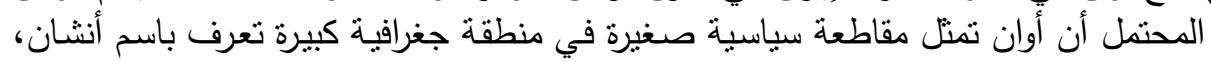
أنظر :

J. Hansman, "Elamites, Aghaemenians and Anshan", Iran, Vol. 10 (1972), P. 102.

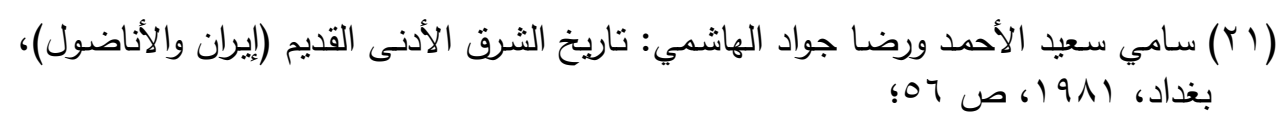

D. Frayne, "Ur III Period (2112 - 2004 B.C)", JNES, Vol. 63, No. 3 (2004), PP. $208-209$.

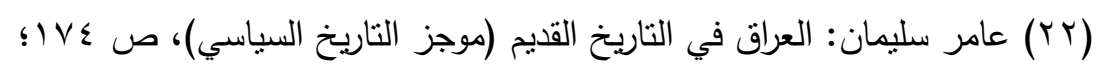

J. Bottero, "Syria Before 2200 B.C.", CAH, Vol.I, Part 2A, Cambridge (1971).

(YT) رشيد الناضوري: تاريخ الثرق الأدنى القديم (بـلاد الرافدين وإيران)، الإسكندرية، ج19 ا، 1971) 


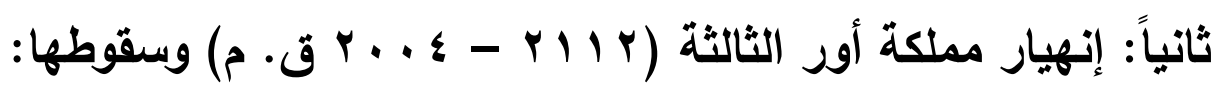

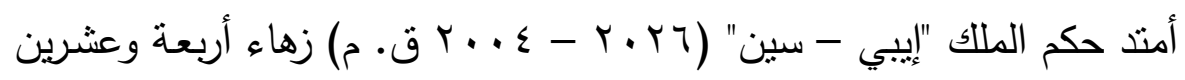

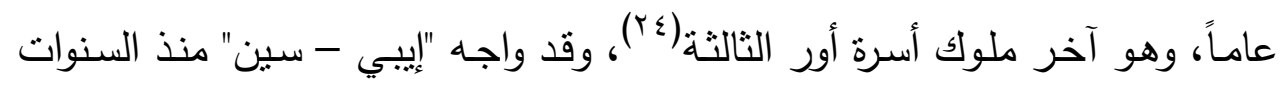

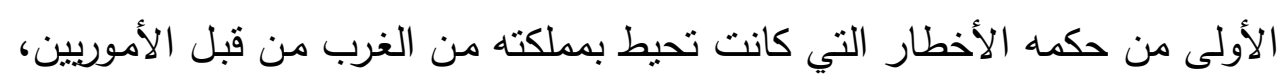

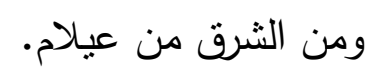

تكرر ذكر الأموريين في النصوص السومرية في تلك الفترة بأسم "مارتو "

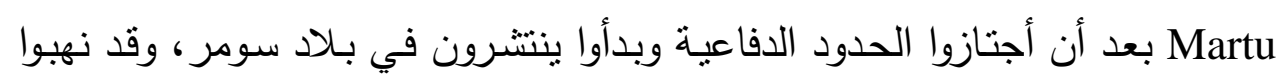

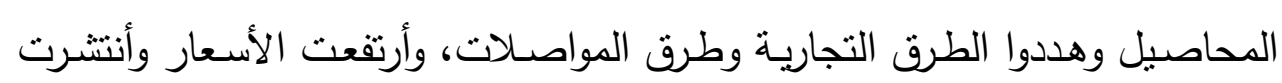

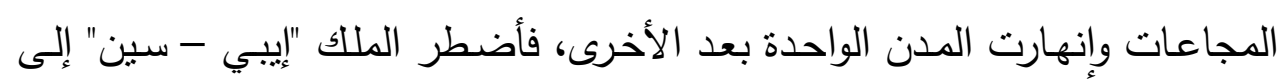

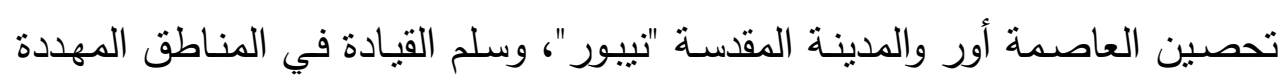

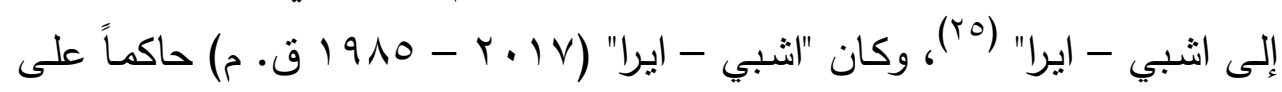

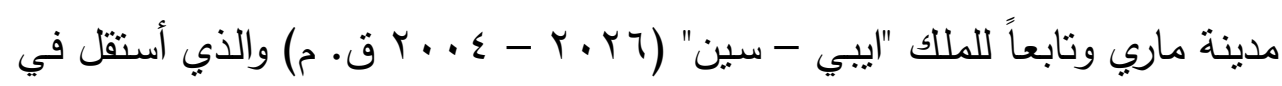

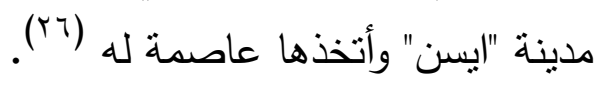

ولاثك في أن ضـعف السلطة المركزية في أواخر عصر أسرة أور الثالثة

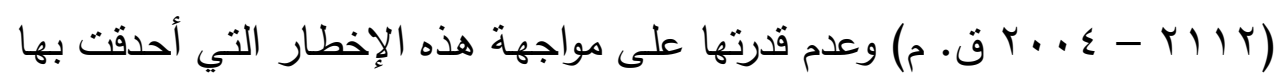

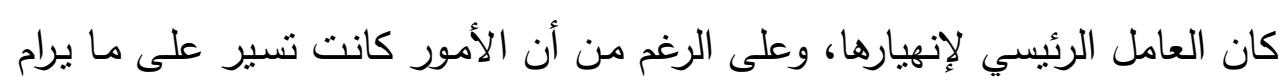

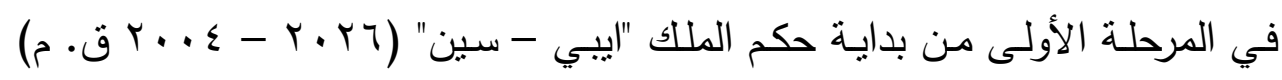

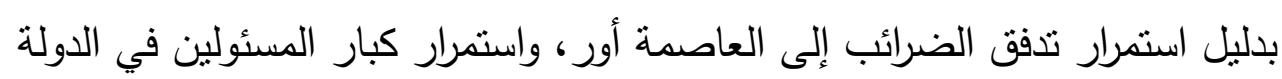

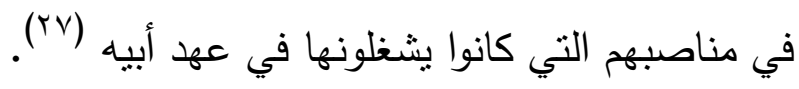

(24) L. Delaporte, Mesopotamia, The Babylonian and Assyrian Civilization, P.36.

(Y0) محمد حرب فرزات وعيد مرعي: دول وحضارات في الثرق العربي القديم، ص Y Y Y Y

(26) H. W. F. Saggs, Everyday Life in Babylonia and Assyria, New York (1965), P. 37.

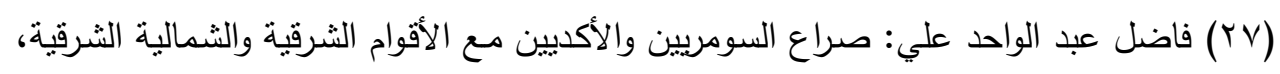

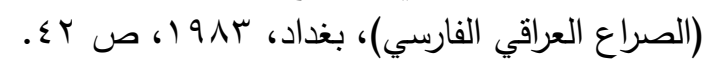




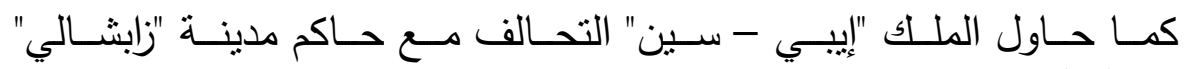
"Zabshali

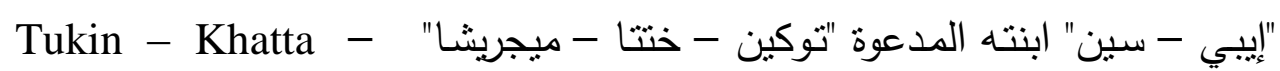
Migrisha

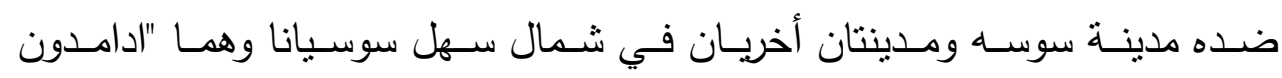

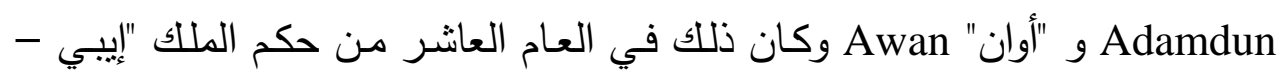

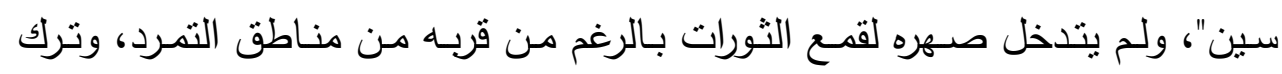

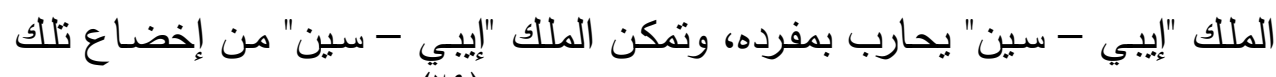

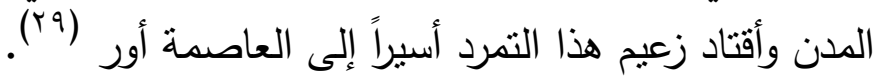

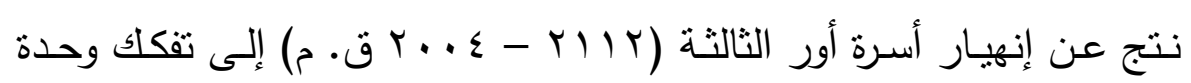

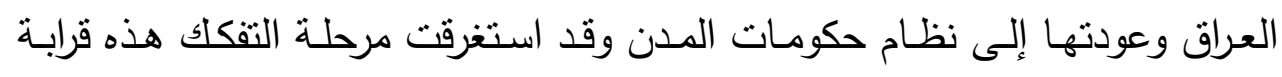

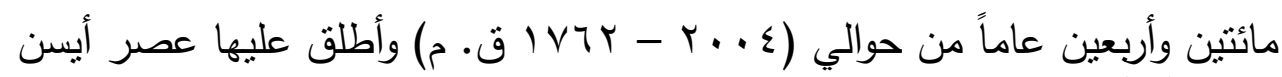

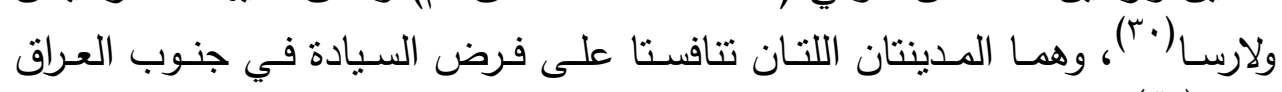

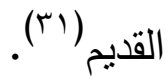

وقد تككن الأموريون من تأسيس العديد من الممالك في سورية والعراق كما في

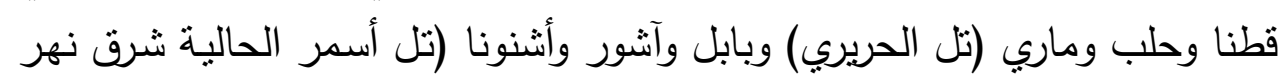
ديالي)، لذلك يطلق على هذا العصر اسم "عصر الأسرات الأمورية"(بr).

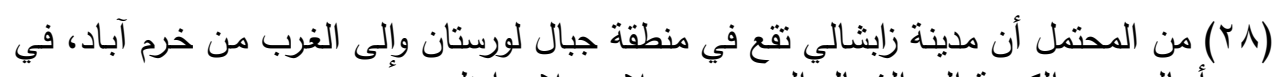

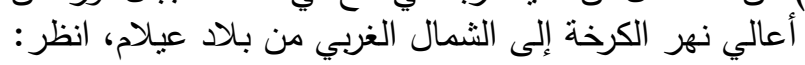

W. Hinz, "Persia C. 2400 - 1800 B.C., ", P. 657.

(29) W. Hinz, "Persia C. 2400 - 1800 B.C.", P. 658;

J. Hansman, "Elamites, Aghaemenians and Anshan", P. 103.

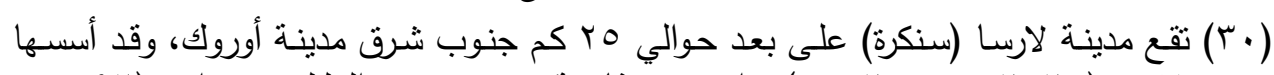

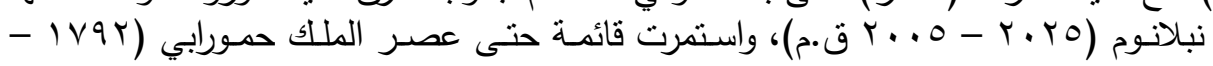

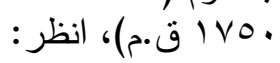

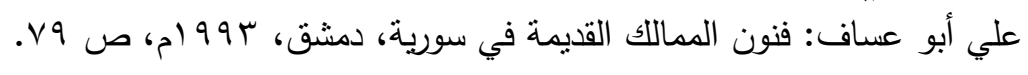

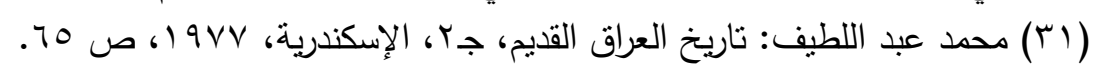

(32) D. Charpin, "The History of Ancient Mesopotamia: An Overview", C.A.N.E., J.M. Sasson, (and Others, eds.), New York (1995), P. 812;

M. Covensky, The Ancient Near Eastern Tradition, New York and London (1966), P. 25. 
يظهر تسلسل انفصال المدن عن السلطة المركزية أن الانفصال بدأ أولاً في

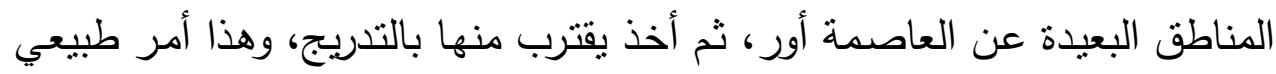

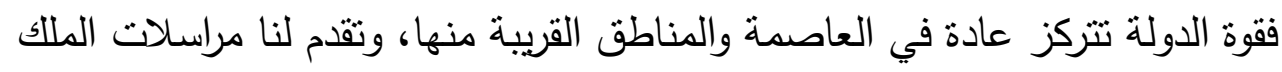

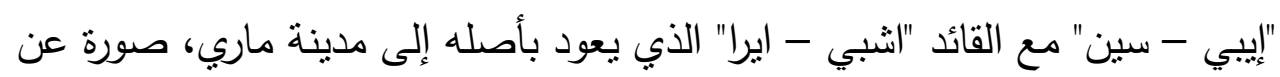

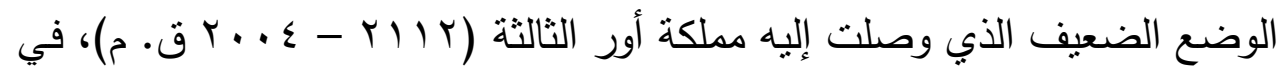

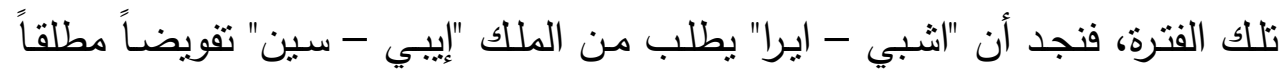

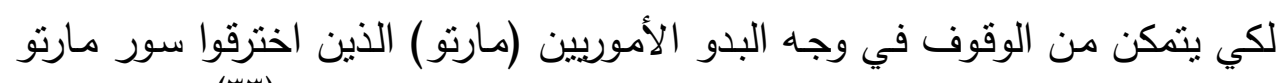

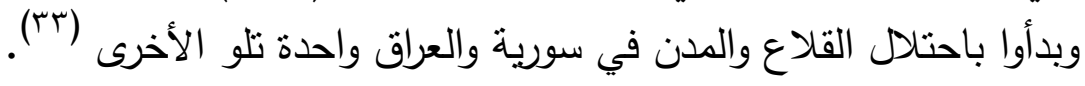

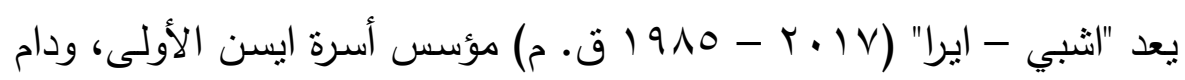

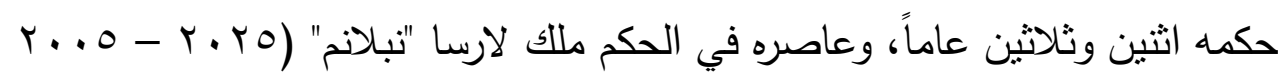

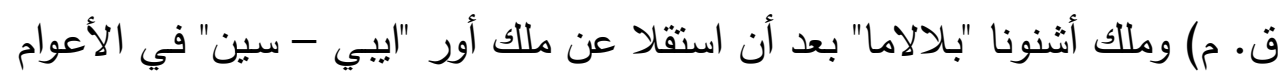

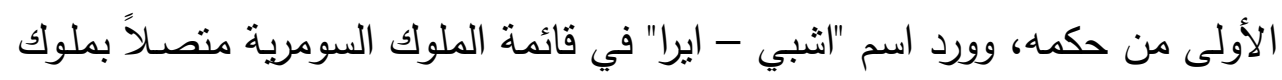

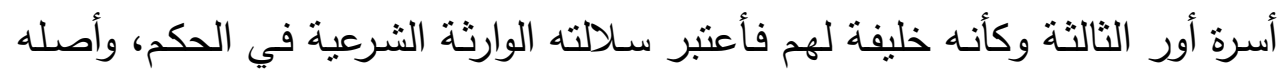

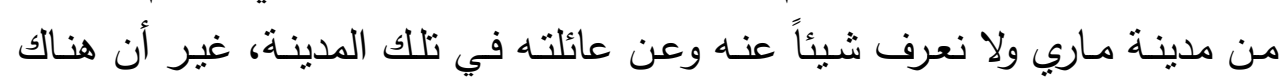

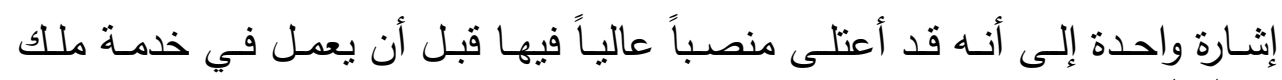

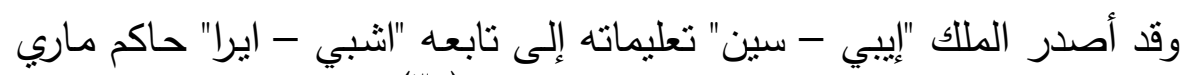

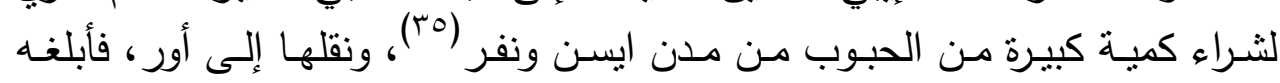

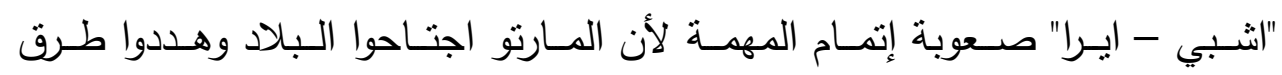

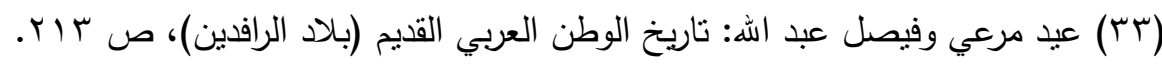

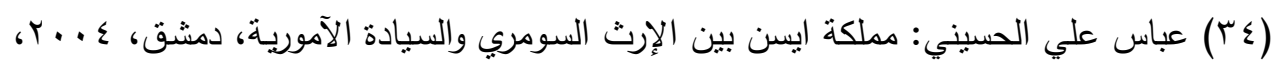
ص سז!

J. G. Macqueen, Babylon, London (1964), P. 32;

E. Sollberger, "New Lists of the King of Ur and Isin, JCS, 8 (1954), P. 135.

(ب0) نفر (نيبور): هي مدينة سومرية مقدسة، وتمتد التلال المعروفة اليوم باسم نفر على مسافة

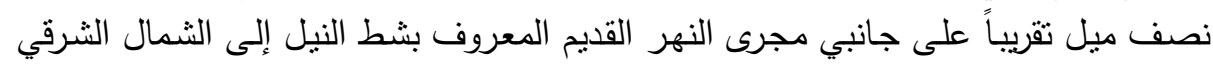
من الديوانية، وهي مركز لعبادة الإله "أنليل"، انظر النياً

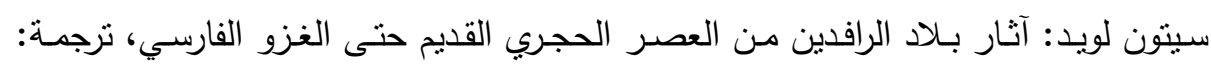

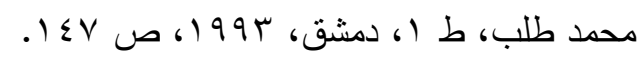


المواصلات المؤدية إلى العاصمة أور، وأنهم على أهبة الاستعداد للهجوم على ايسن

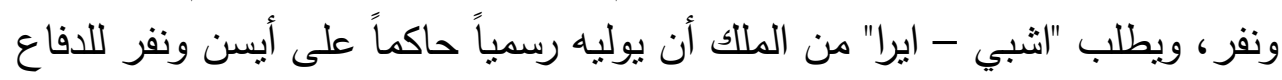

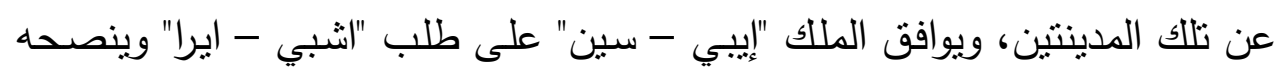

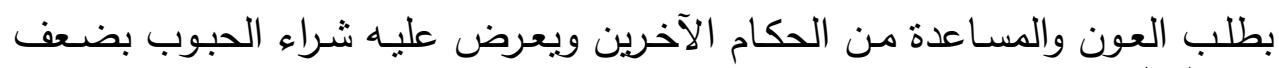

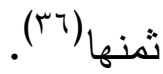

بدأت الأوضاع في التذهور والاضطراب وذلك نتيجة لهجمات القبائل الآمورية

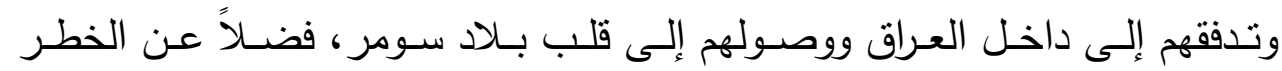

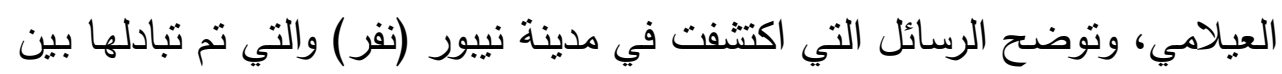

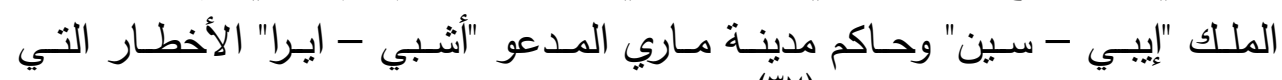

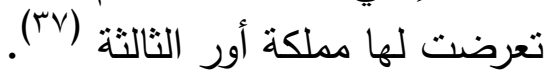

سوف يتتاول الباحث الرسائل الثلاث التي يمكن الإستدلال منها على الإنهيار المؤكد لأسرة أور الثالثة في عهد الملك "إيبي - سين".

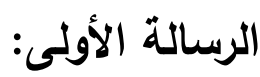
جاء في نص الرسالة التي بعثها "اشبي - ايرا" إلى الملك "ايبي - سين" ما يلي:

" إلى "إيبي - سين" ملكي، هكذا يقول خادمك "اثشبي - ايرا" : لقد أمرتني

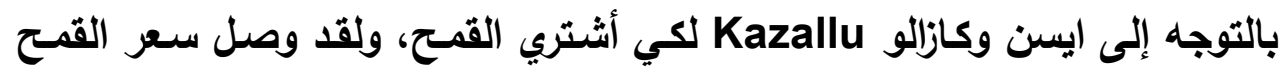

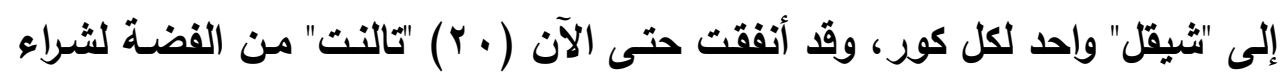

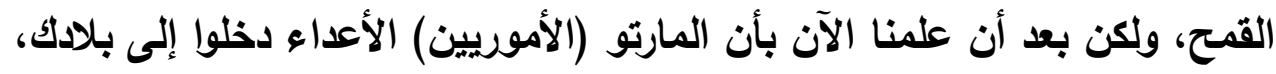

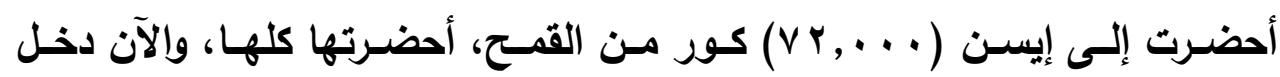

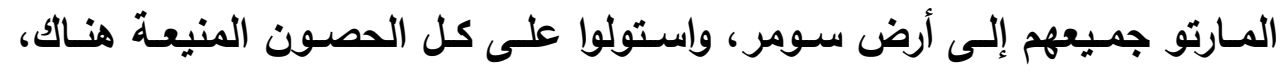

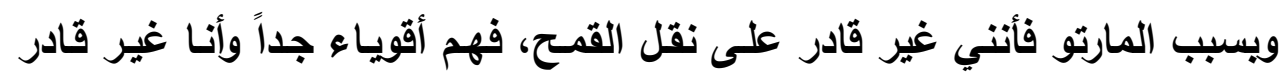

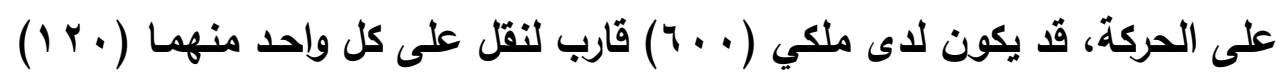

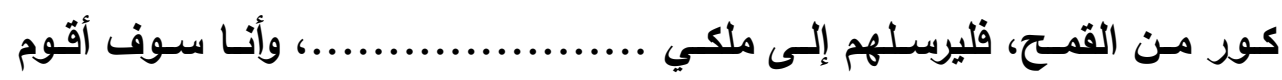

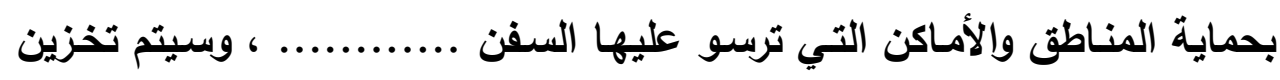

(36) G. Roux, Ancient Iraq, Second edition, penguin Books, England (1980), P. 167.

(37) G. Roux, Ancient Iraq, P. 167. 


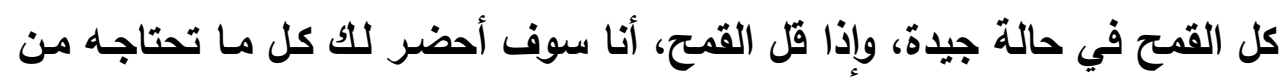

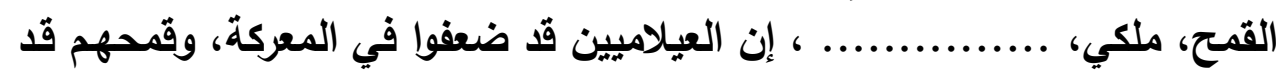

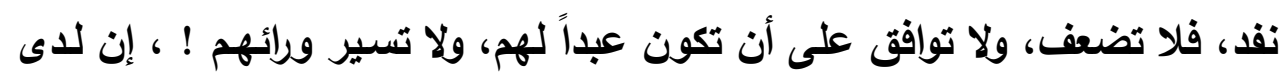

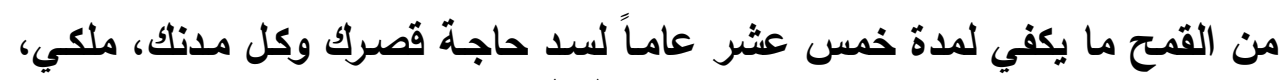

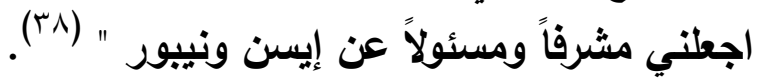

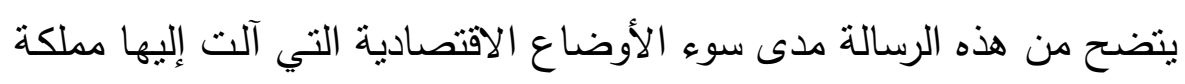

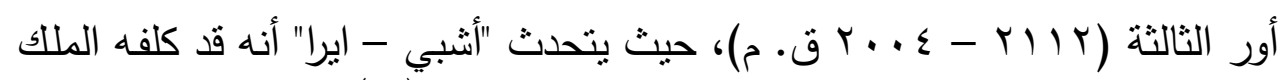

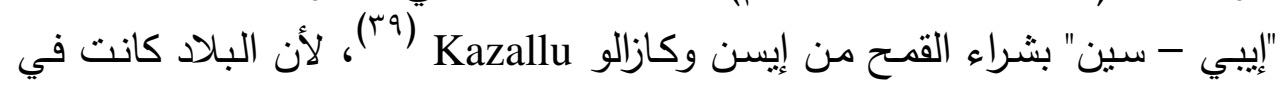

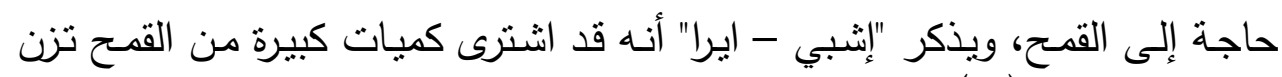

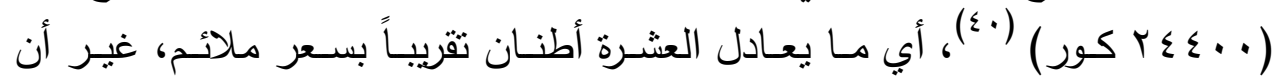

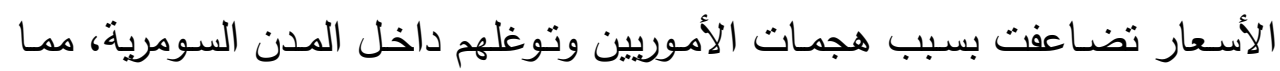

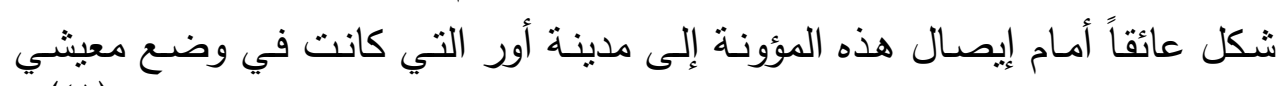

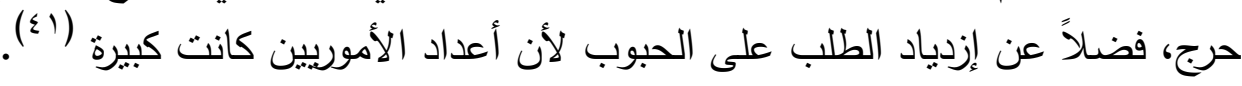
وذكر "إثببي - ايرا" أنه لم يكن قادراً على إيصال الحبوب التي قام بشرائها

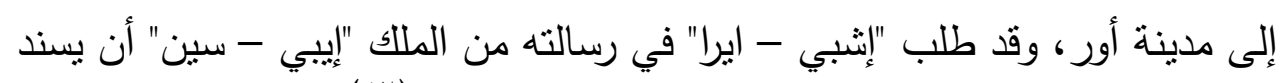

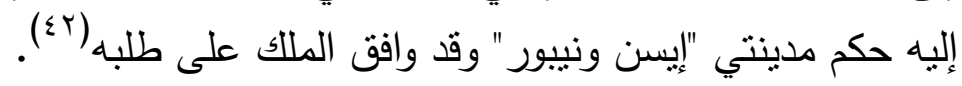

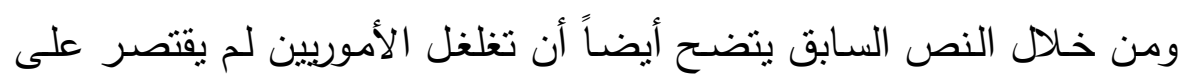

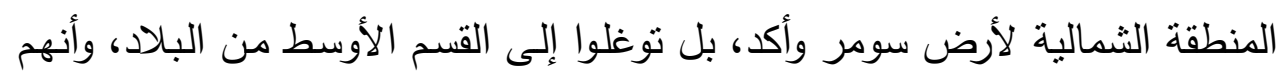

(38) A. Kubrt, The Ancient Near East C. 3000 - 330 B.C., PP. 70 - 71.

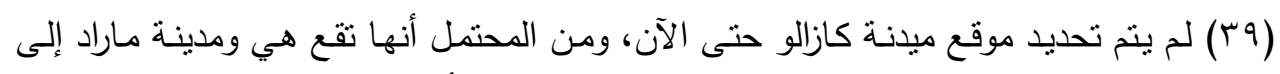

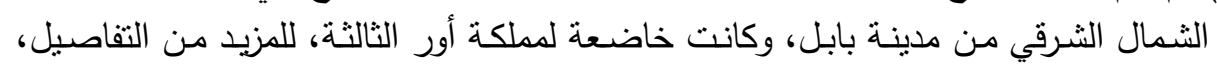

R. de Boer, "Marad in the Early old Babylonian Period : Its Kings, Chronology, and Isin's Influence", JCS, Vol. 65 (2013), P. 74.

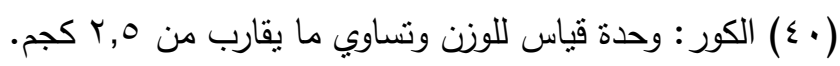

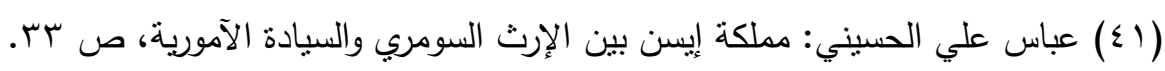

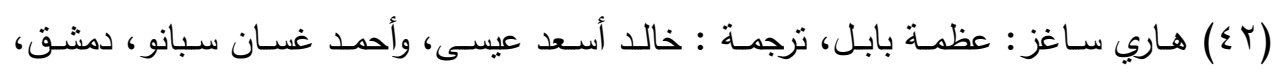

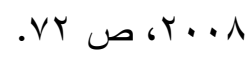




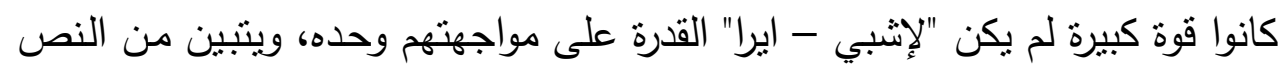

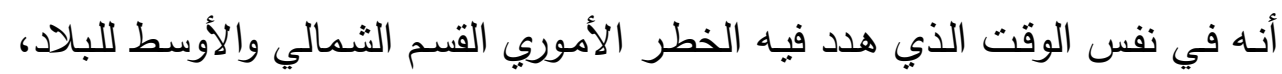

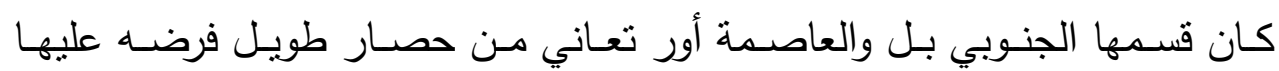

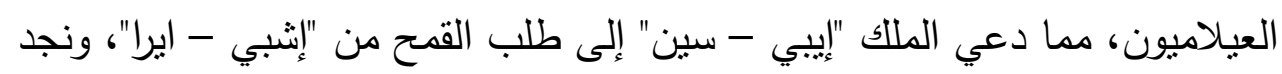
"إثبي - ايرا" يحث سيده الملك "إيبي - سين" على الصمود أمام الحصار العيلامي دئي الذي ضعف، ويشجعه بأن لايه الكثير من القمح لإمداده بـه، ولكن هذا التشجيع لم يكن بدون غرض، فنجد "إثبي - ايرا" في نهاية الرسالة يطلب من الملك "إيبي -

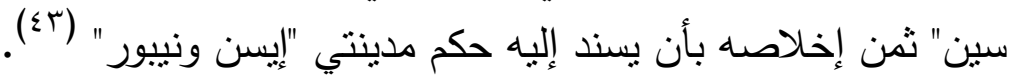
مـن المحتمل أن "إثـبي - ايـرا" كان مخلصـاً للملك "إيبي - سين" في أول الأمر ، إلا أن سوء الأوضاع السياسية والاقتصادية كانتا من العوامل التي أدت إلى إنى

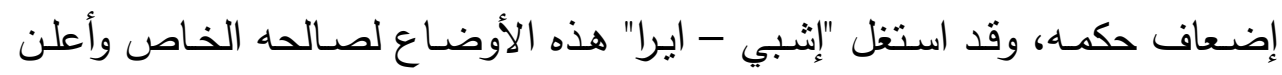

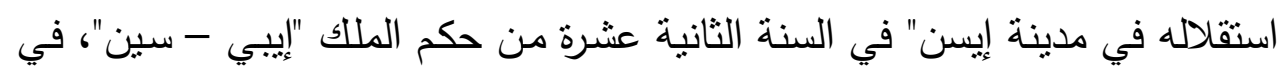

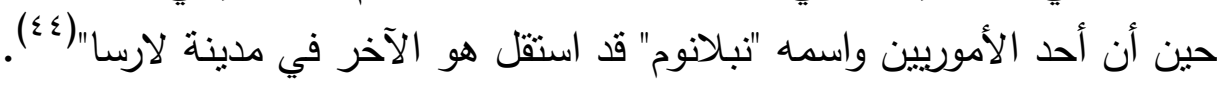
اسـتقل "إثـبي - ايـرا" بحكم مدينـة إيسـن (خريطـة رقم r)، في حوالي عـام

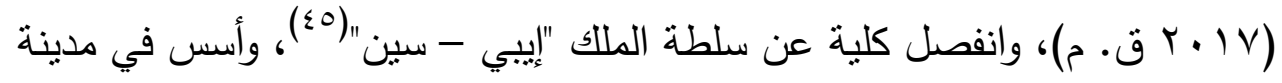
إيسن أسرة مستقلة منذ العام الثاني عشر من حكم الملك "إيبي - سين" وبدأ يؤرخ

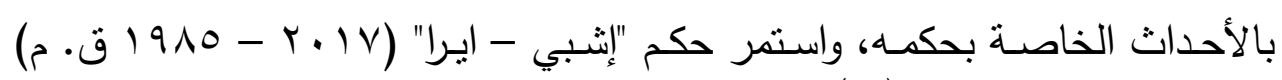
زهاء ثناثة وثلاثين عاماً (ٓ؛)، وفي الواقع كان "إثبي - ايرا" يعتبر أقوى حاكم في

$$
\text { وكذلك: }
$$

A. Kubrt, The Ancient Near East C. 3000 - 330 B.C., P. 71.

(§ §) فاضل عبد الواحد علي: صراع السومريين والأكديين، مع الأقوام الثرقية والثمالية الثرقية،

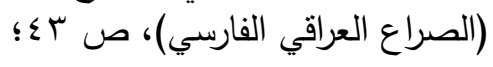

C. J. Gadd, "Babylonia C. 2120 - 1800 B. C.", P. 613.

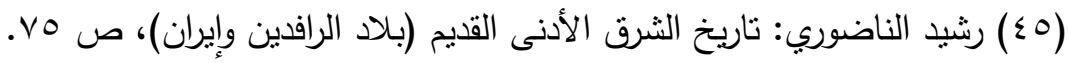

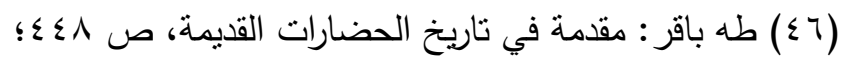

$$
\begin{aligned}
& \text { وكذللك: بات }
\end{aligned}
$$

M. V. de Mieroop, "Documents from the Reigns of Išbi - Erra and Šuilišu", JAOS, Vol. 3, No. 2 (1991), PP. 366 - 372. 
البلاد إلا أنه لم يستطع الإنفراد بالسلطة ذلك لأن سامياً غربياً آخر يدعى "نبلانوم"

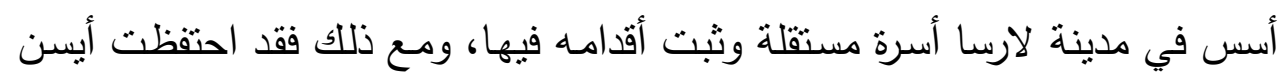

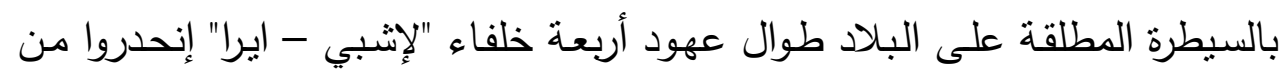

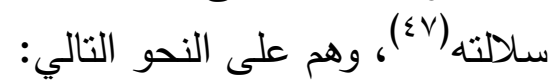

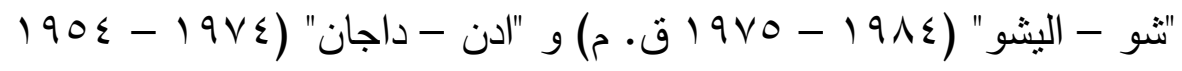

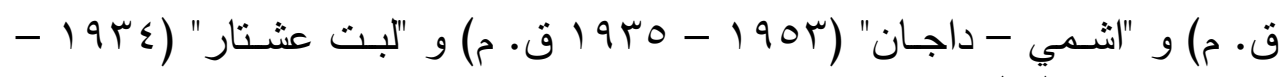

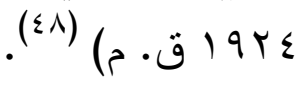

وقد قام "إثببي - ايرا" باحتلال مدينة نييور (نفر) عاصمة سومر الدينية،

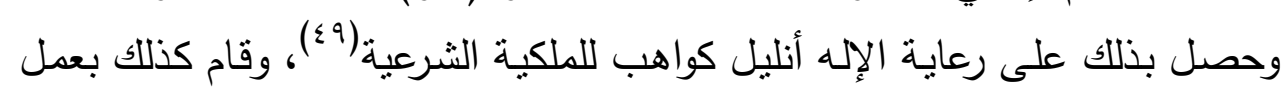

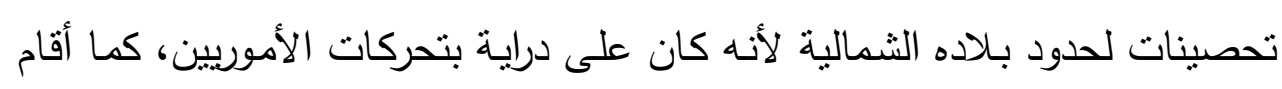

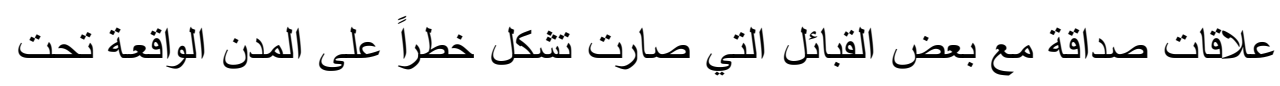

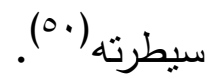

ولم يكتف "إنبي - ايرا" بذلك بل عمل على بسط نفوذه إلى مناطق نفوذ

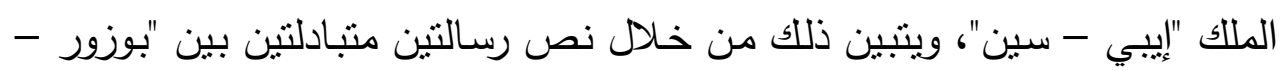

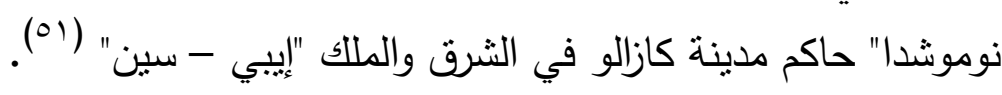

( \& أنطون مورنكات: تاريخ الثرق الأدنى القديم، تعريب: توفيق سليمان وعلي أبو عساف

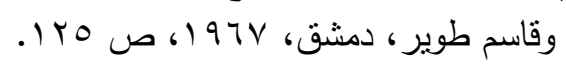

(48) A. Kubrt, The Ancient Near East C. 3000 - 330 B.C., P. 79.

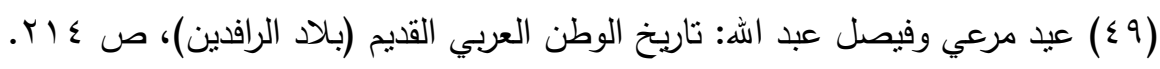

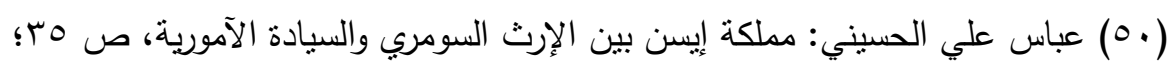

$$
\begin{aligned}
& \text { وكذلك: }
\end{aligned}
$$

T. Jacobsen, "The reign of Ibbisuen", JCS, Vol. 7 (1953), P. 120.

$$
\text { وكذبل }
$$

T. Jacobsen, "The reign of Ibbisuen", PP. 36-47. 


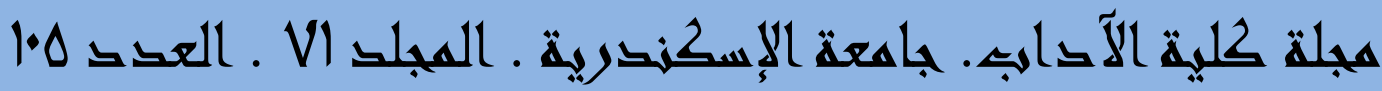

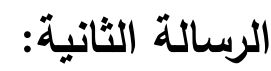

جاء في نص الرسالة التي بعثها "بوزور - نوموشدا" حاكم مدينة كازالو إلى الملك "إيبي - سين " ما يلي: نصي: الرساء

" إلـى " إيبـي - سـين"، ملكي، هكذا يقول خادمـك "بـوزور - نوموشــا

: Puzur - Numushda

لقد (آتي إلس) رسسول من "اثببي - ايـرا ".............. (ومعسه) الرسـالة

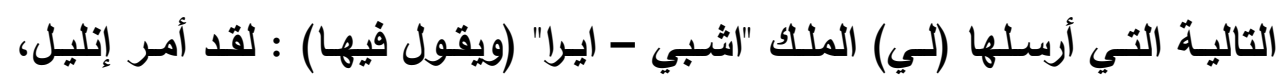

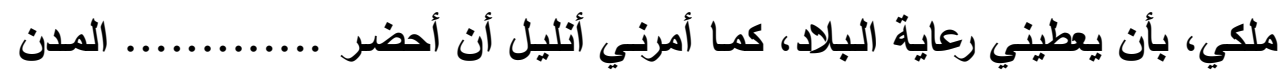

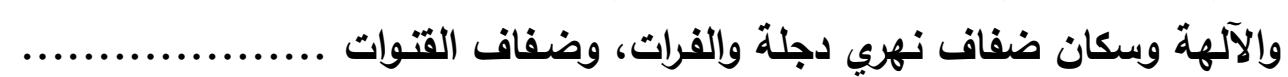

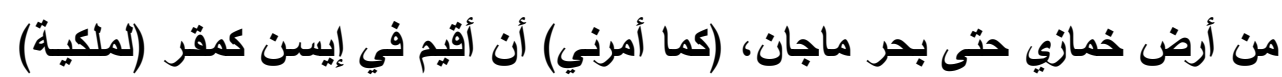

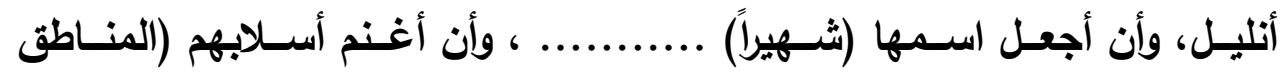

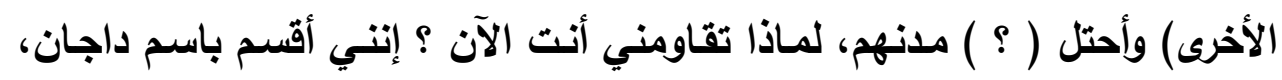

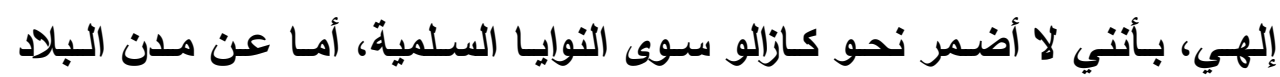

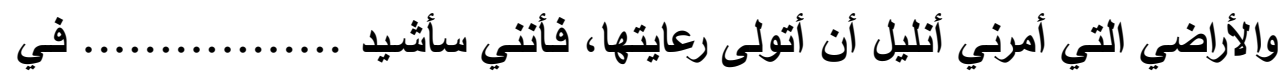

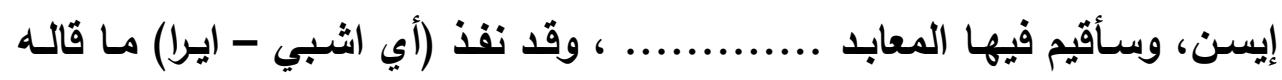

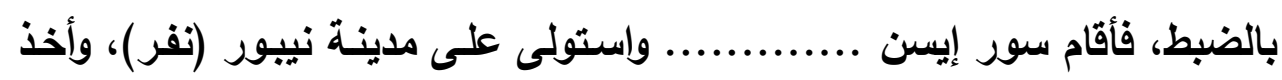

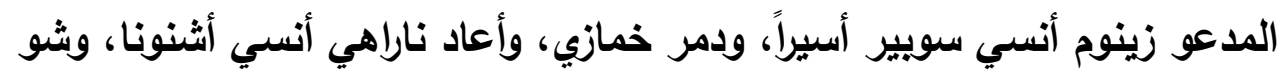

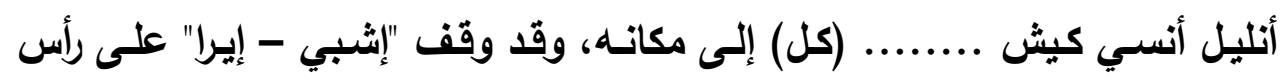

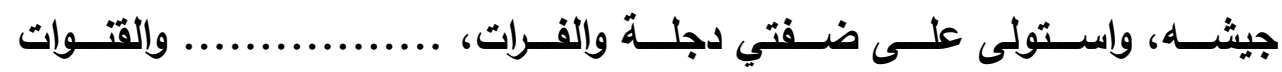

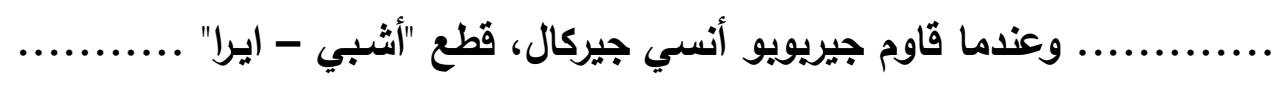

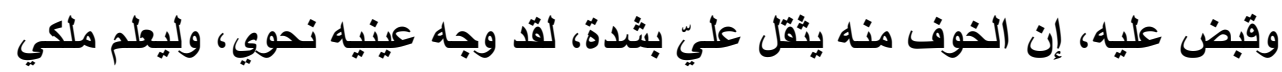

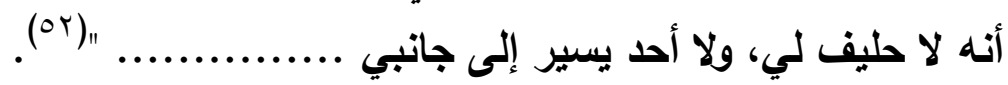

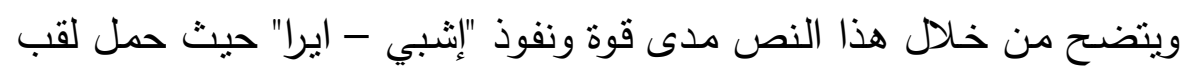

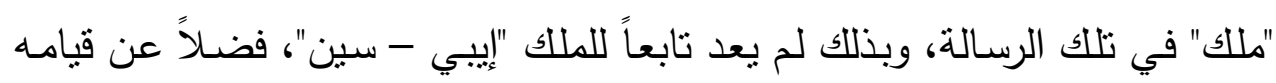

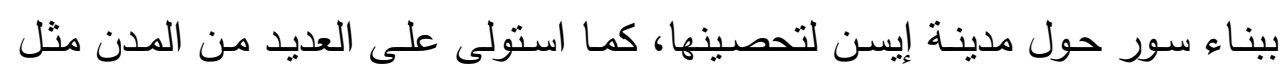


نيبور عاصمة سومر الدينيـة وكيش وأنثـنونا وخمـازي، فضـلاً عن ذكر "بوزور نوموشدا" حاكم مدينـة كازالو في رسالته إلى الملك "إيبي - سين" بأنه لا يستطيع مواجهة "إنشبي - ايـرا " بمفرده، حيث أخبر الملك "إيبي - سبين" بأنـه ليس لديـه حليف.

ونستنتنج من تلك الرسـالة أيضـاً محاولـة "إثـبي - ايـرا" لضـم مدينـة كازالو

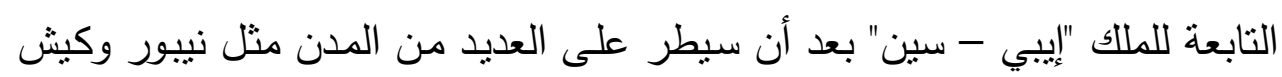
وغيرها من المدن (بابعة لمائي

فقد بـأت مملكة "إيبي - سين" بـالتقلص تدريجياً حتى أصبحت مؤلفة من

مدينة أور، وبالرغم من أن بعض حكام المناطق الأخرى كانوا موالين للملك "إيبي -

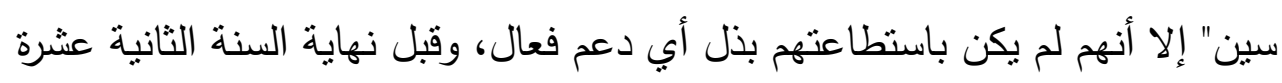
من حكم الملك "إيبي - سين" أعلن "إثببي - ايرا" نفسـه ملكاً في مدينـة إيسن وبدأ

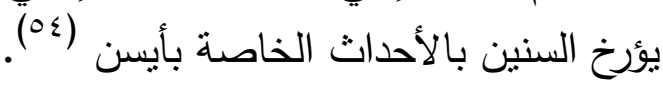

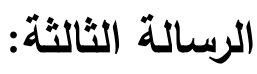
وقد قام الملك "إيبي - سين " بالرد على رسالة|*) "بوزور - نوموشدا" حاكم مدينة كازالو حيث جاء فيها ما يلي:

" إلى بوزور - نوموشدا، حاكم مدينة كازلو، هكذا يتحدث ملكل "إيبي -

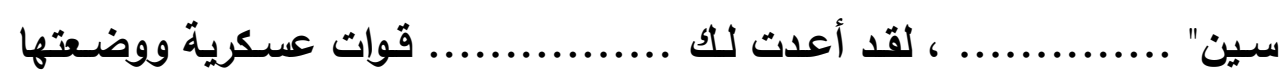
تحت تصرفك كحاكم كازلو ................ فلماذا أرسلت إليّ (تقول): إن "إثبي -

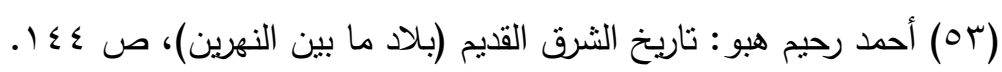

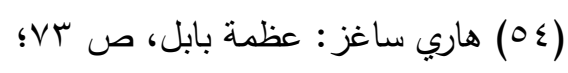

$$
\begin{aligned}
& \text { وكذلك: }
\end{aligned}
$$

F. J. Stephens, "New Date Formulae of the Isin Dynasty", RA, Vol. 33, No. 1 (1936), P. 13.

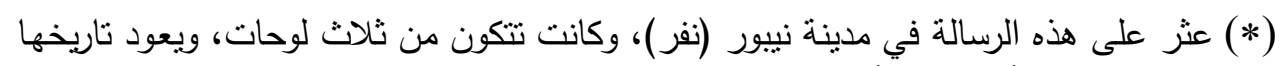

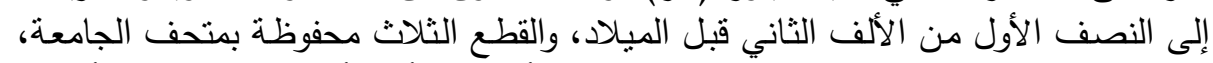

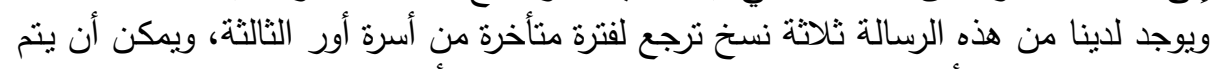

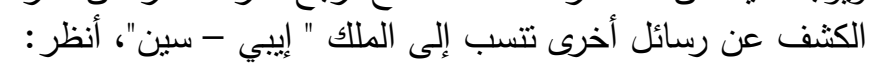

S. N. Kramer, "A Sumerian Letter", ANET, Princeton (1969), P. 480. 


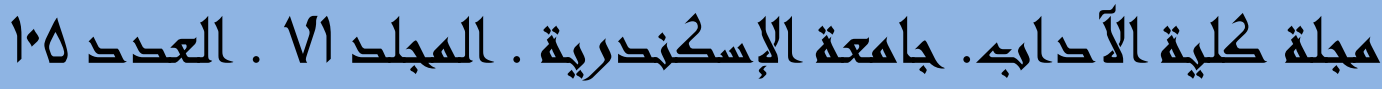

ايرا" وجه عينيه نحوك، وكيف إنك لم تعرف متى سيعود "إثببي - ايرا" إلى أرضـه

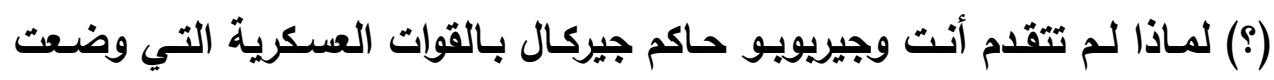

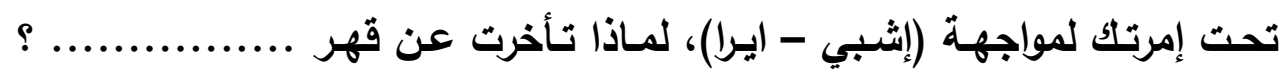

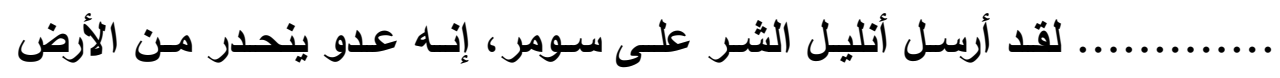

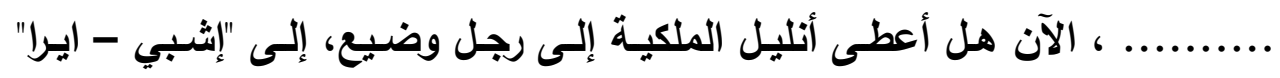

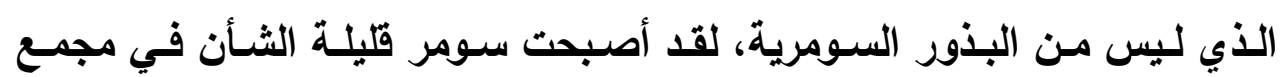

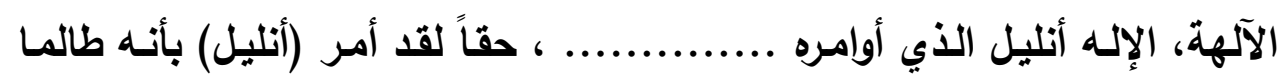
وجد الأثـرار في أور، فِإن "إثشبي - ايـرا"، رجل مـاري، سـوف يمـزق أسسـها،

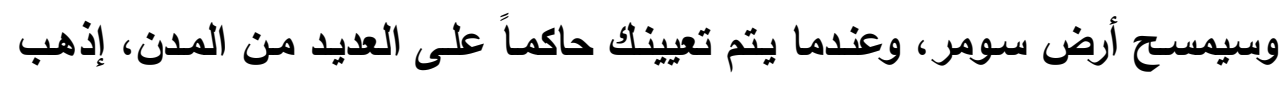

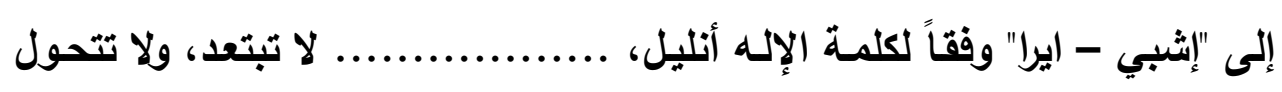

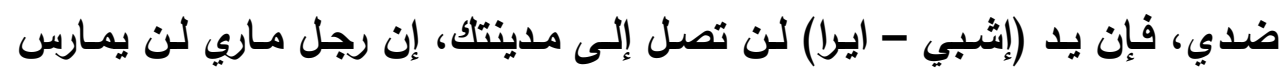

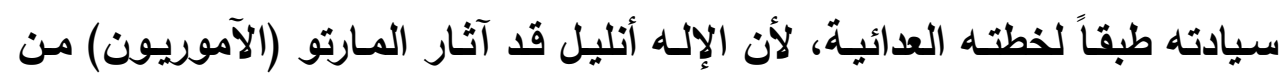

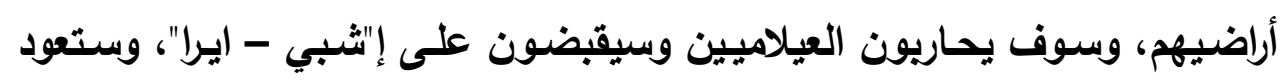

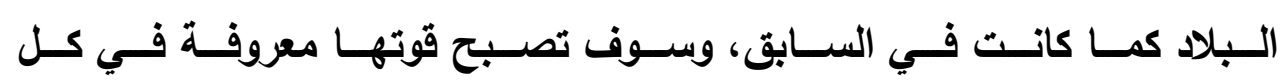
(00) الأراضي.

يتضح من رد الملك "إيبي - سين" في رسالته الموجهة إلى تابعه "بوزور -

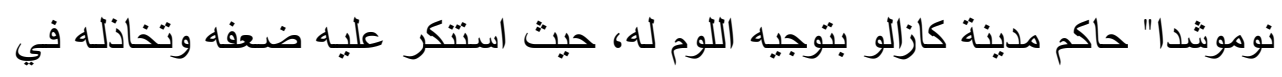

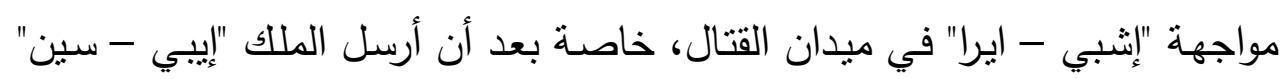

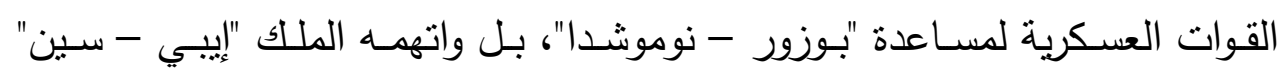

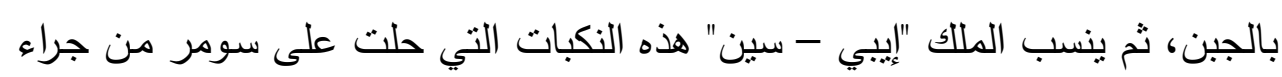

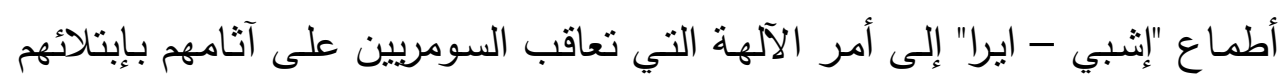
بهذه المحن.

في نهاية الرسالة نجد الملك "إيبي - سين" يحث حاكم مدينة كازالو على عدم

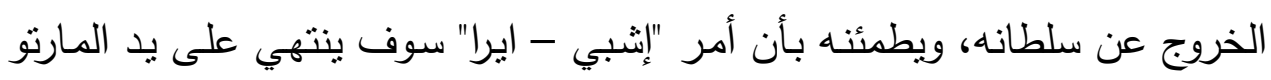

(55) S. N. Kramer, "A Sumerian Letter", ANET, (1969), PP. 480 - 481. 
(الآموريين) الذين جاءوا إلى البلاد بأمر الإده أنليل، وأنهم سوف يقضون على

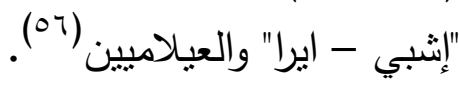

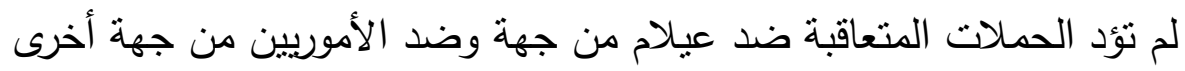

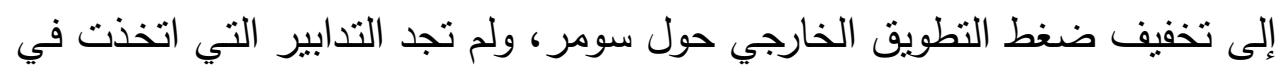

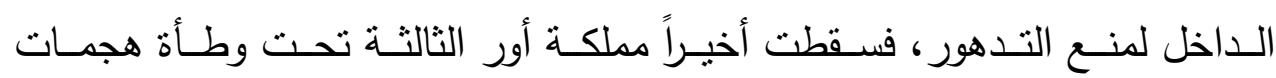

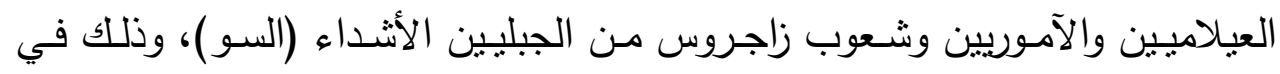

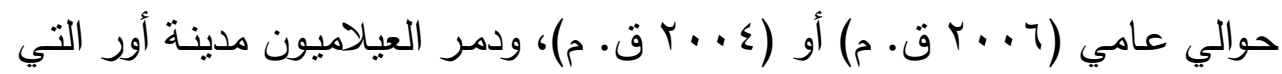

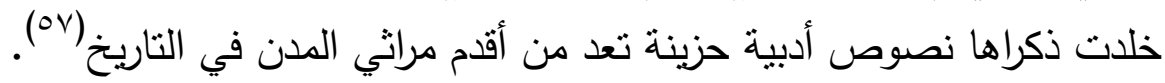

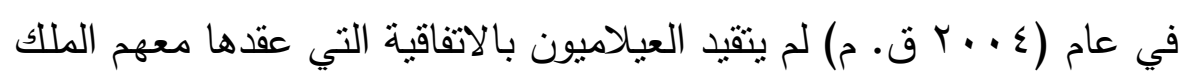

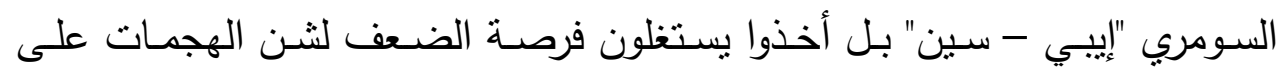

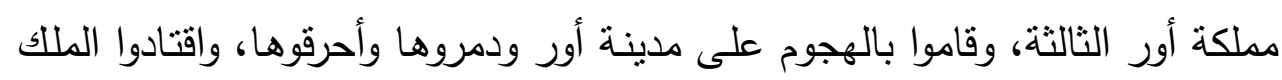

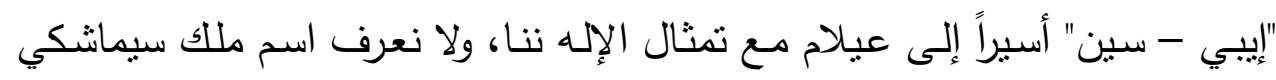

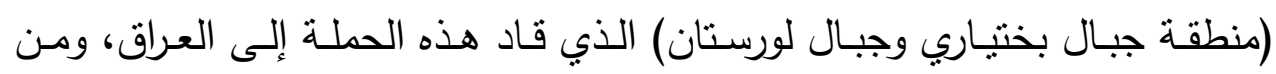

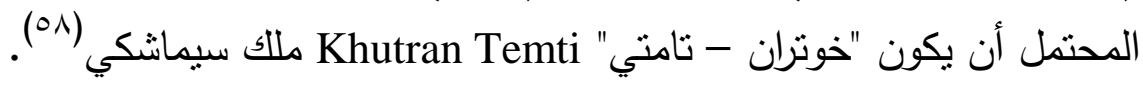
بعد سقوط أور تم الاعتراف بشرعية سيادة "إثببي - ايرا" على المناطق التي

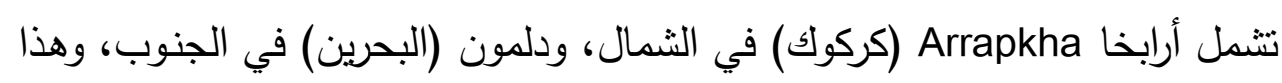

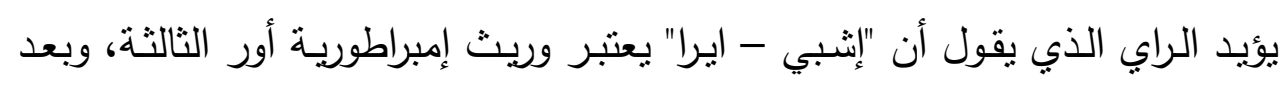

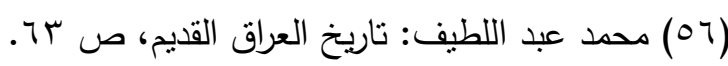

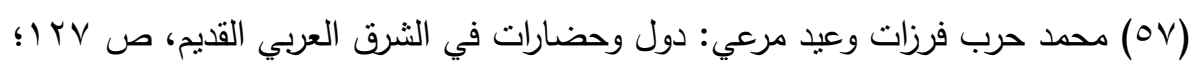

$$
\text { واللمزيد من الثفاصيل، انظر : }
$$

S. N. Kramer, "Sumerian Lamentation", Lamentation over the Destruction of Sumer and Ur, ANET, Princeton (1969), PP. 611 619.

$$
\text { صامي سعيد الأحمد ورضا جواد الهاثمي: تاريخ الثرق الأدنى القديم (إيران والأناضول)، }
$$

J. Oates, Babylon, PP. 49 - 52;

M. Liverani, The Ancient Near East: History, Society and Economy, London (2013), P. 174. 
ثمـان سنوات من دمار مدينـة أور تمكن "إثببي - ايرا" من طرد الحاميـة العيلاميـة منها، وقد عمل فيما بعد على إعادة بناء المدينة وأعاد تمثال إله القمر ننا وهو الإلهد

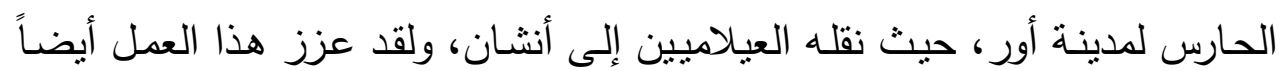

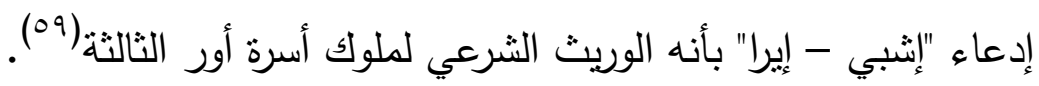
كان اعتزاز "إثثبي - ايرا" بالثقافة السومرية عالياً حيث بقيت اللغة السومرية

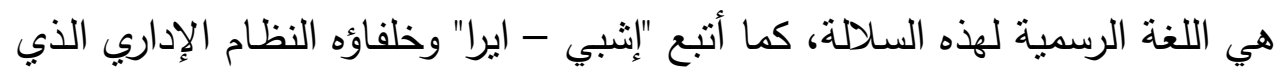

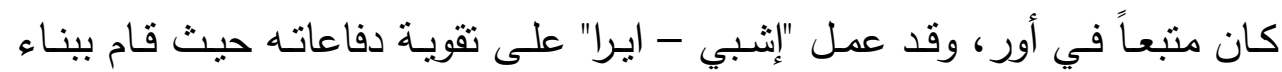

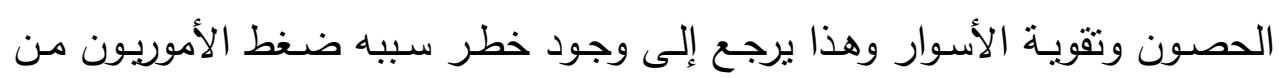

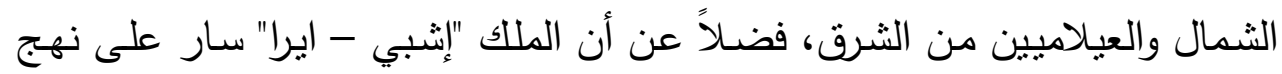

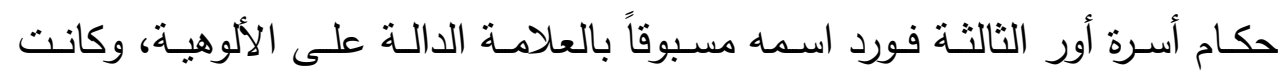

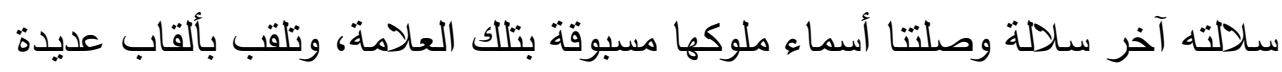
منها "إله بلاده" وملك بلاده، وسيد بلاده"، ويوجد نصاً على ختم أسطواني جاء فيه:

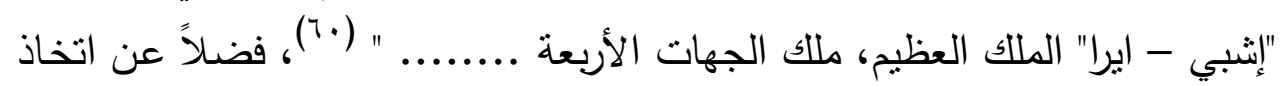

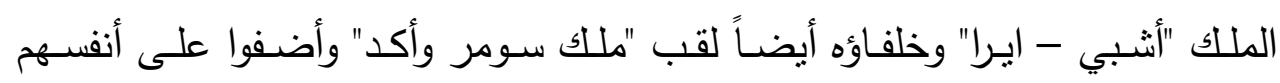

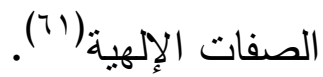

وجدير بالذكر أن "إنثبي - ايرا" حاول أن يعيد دبلوماسية ملوك أسـرة أور

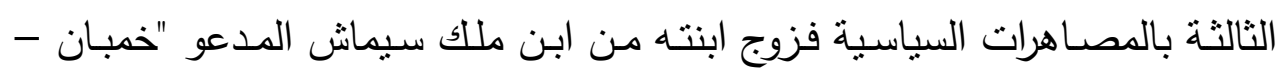

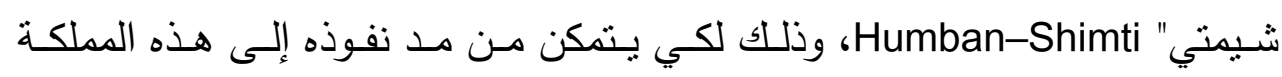

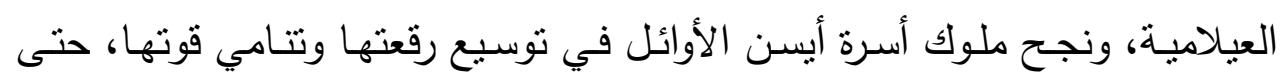

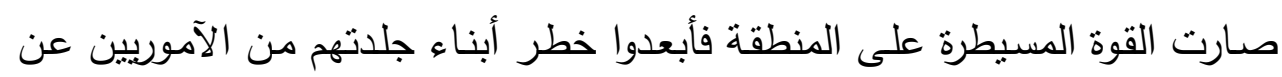

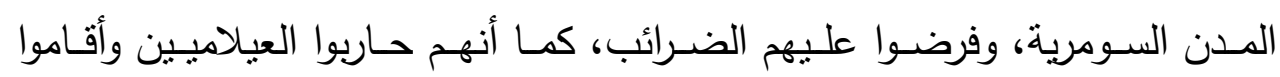
الحصون لصد هجمات أعدائهم، فأحتفظت أيسن بالسبطرة شبه المطلقة على البلاد

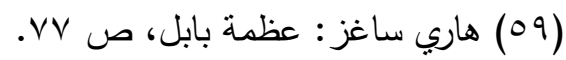

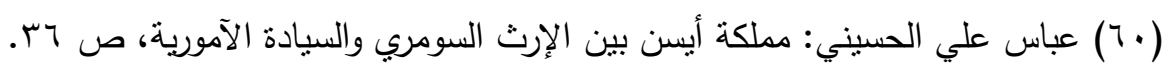

(61) L. Delaporte, Mesopotamia the Babylonian and Assyrian Civilization, P. 37. 
طوال عهود الملوك الأربعة الأوائل، وبهذا بدا وكأن وحدة البلاد المركزية قد تحققت

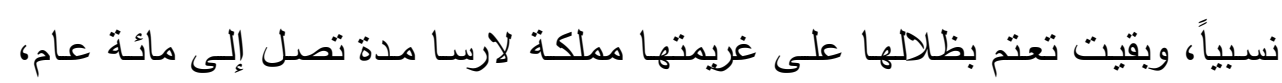
حيث رضي ملك لارسا الأموري "نبلانم" بما لا يزبد على المدينة التي أحكم سيطرته عليها (Tr)

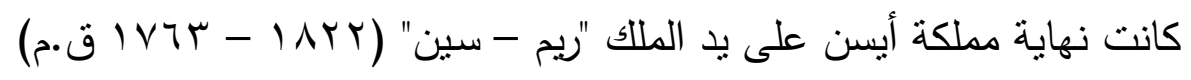
ملك لارسا وذلك في عام (ع Vو أق. م)، واستمرت سلالة لارسا المنافسة لها في

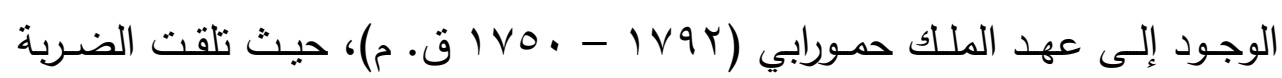

القاضية بدورها على يده وذلك في عام (rTVT ا ق. م) (rT).

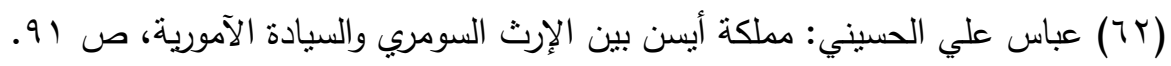

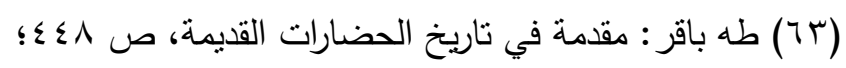
للمزيد من التفاصيل، انظر : لناصه

M. A. Fitzgerald, The Rulers of Larsa, Yale University, New Haven (2002). 


\section{نتائج البحث:}

ا - تمثل أسرة أور الثالثة آخر عهدنا بالحكم السومري الخالص وذلك يمثل نقلة

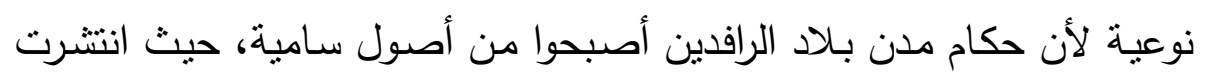

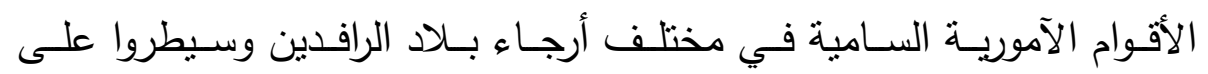
الأوضاع السياسية وأسسوا سلالات حاكمة.

r - أوضحت الرسائل المتبادلة بين الملك "إيبي - سين" و "إثببي - إيرا" حاكم

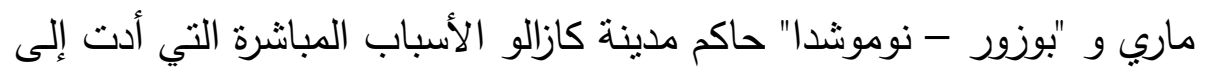

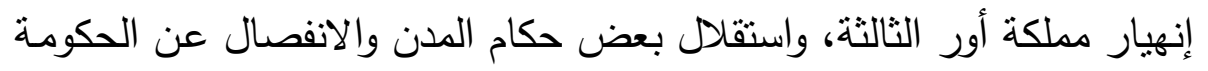

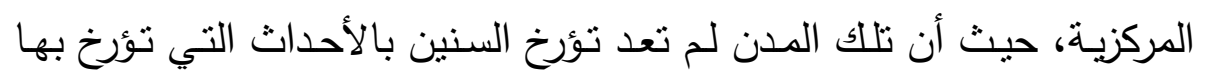

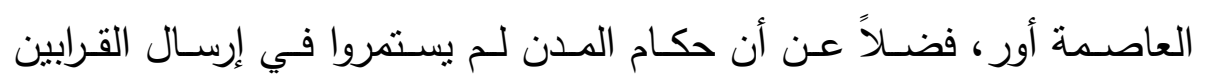

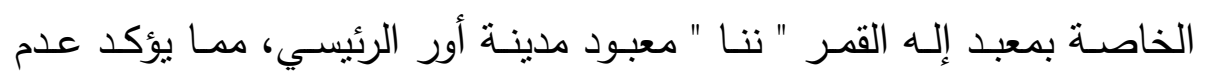

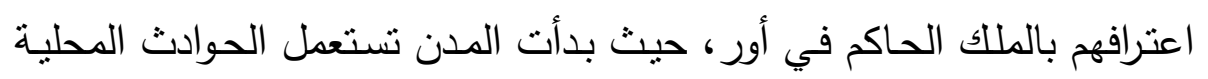

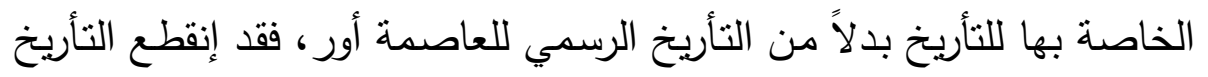

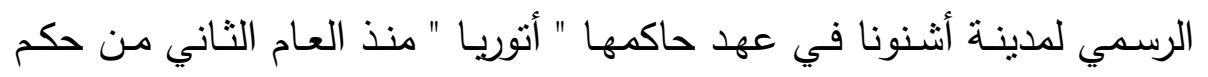

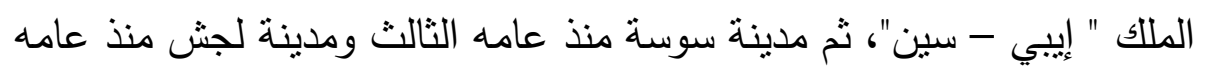
الخامس ومدينة أوما منذ عامه السادس ومدينة نفر منذ عامه السابع ومدينة إيسن منذ عامه الثاني عشر .

r - نتنج عن احتلال "إثبـي - ايرا " مدينـة نيبور (نفر) عاصمة سومر الدينيـة

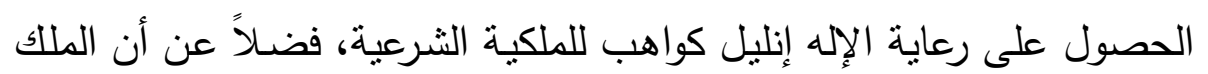

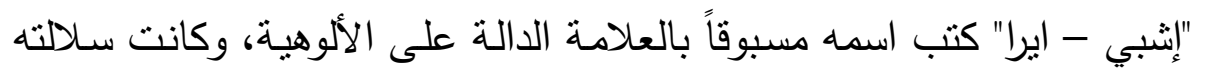
آخر سلالة وصلنتا أسماء ملوكها مسبوقة بتلك العلامة.

ع - تأثرت أسرة ايسن الأولى بالحضارة السومرية حيث ظلت اللغة السومرية هي

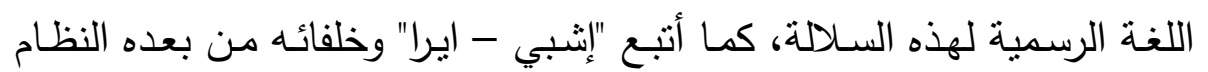

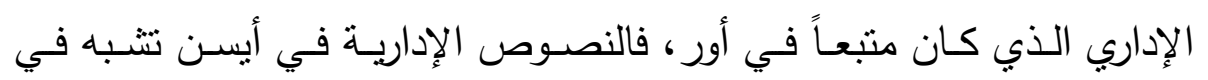
طابعها ومضمونها تماماً نصوص سلالة أور الثالثة. 
ه - ألفت الكثير من القطع الأدبية في عصر سلالة أيسن الأولى، وأعادوا كذلك

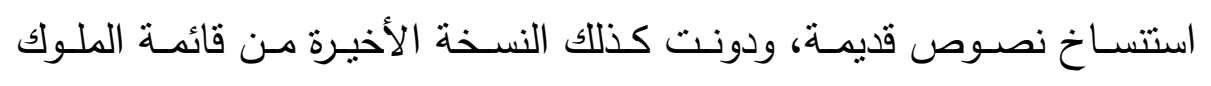
السومرية، والهدف منها إضفاء الصفة الثرعية على ملوك إيسن بأنهم ورثة ودنة

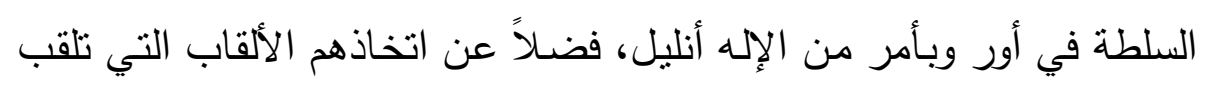

$$
\text { بها الحكام السومريون. }
$$

1 - تشير الرسـائل المنبادلة بين الملك "ايبي - سين" و "اثشبي - ايرا" إلى سوء

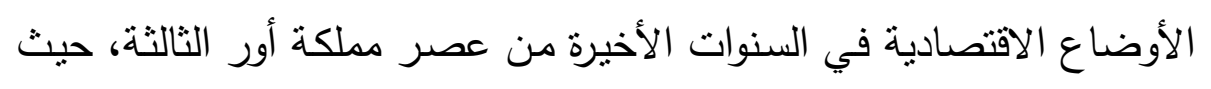

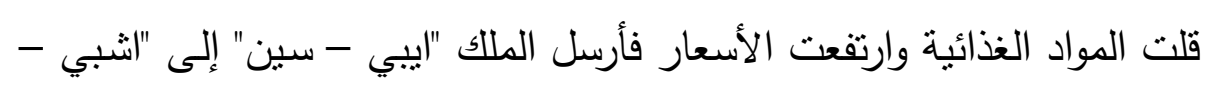

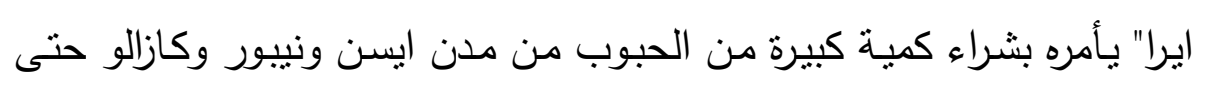

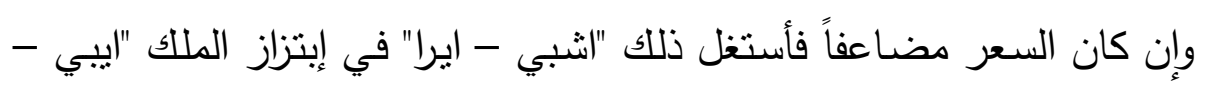

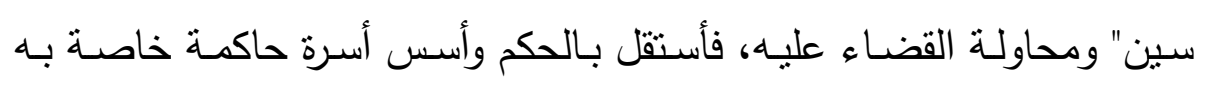

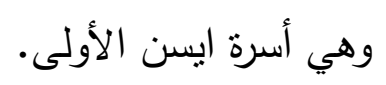




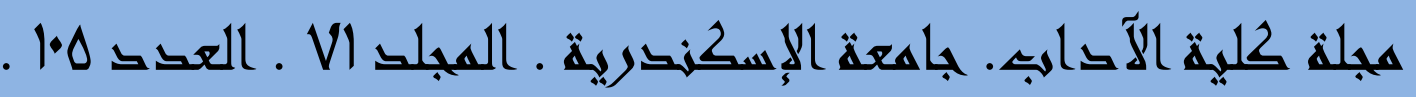

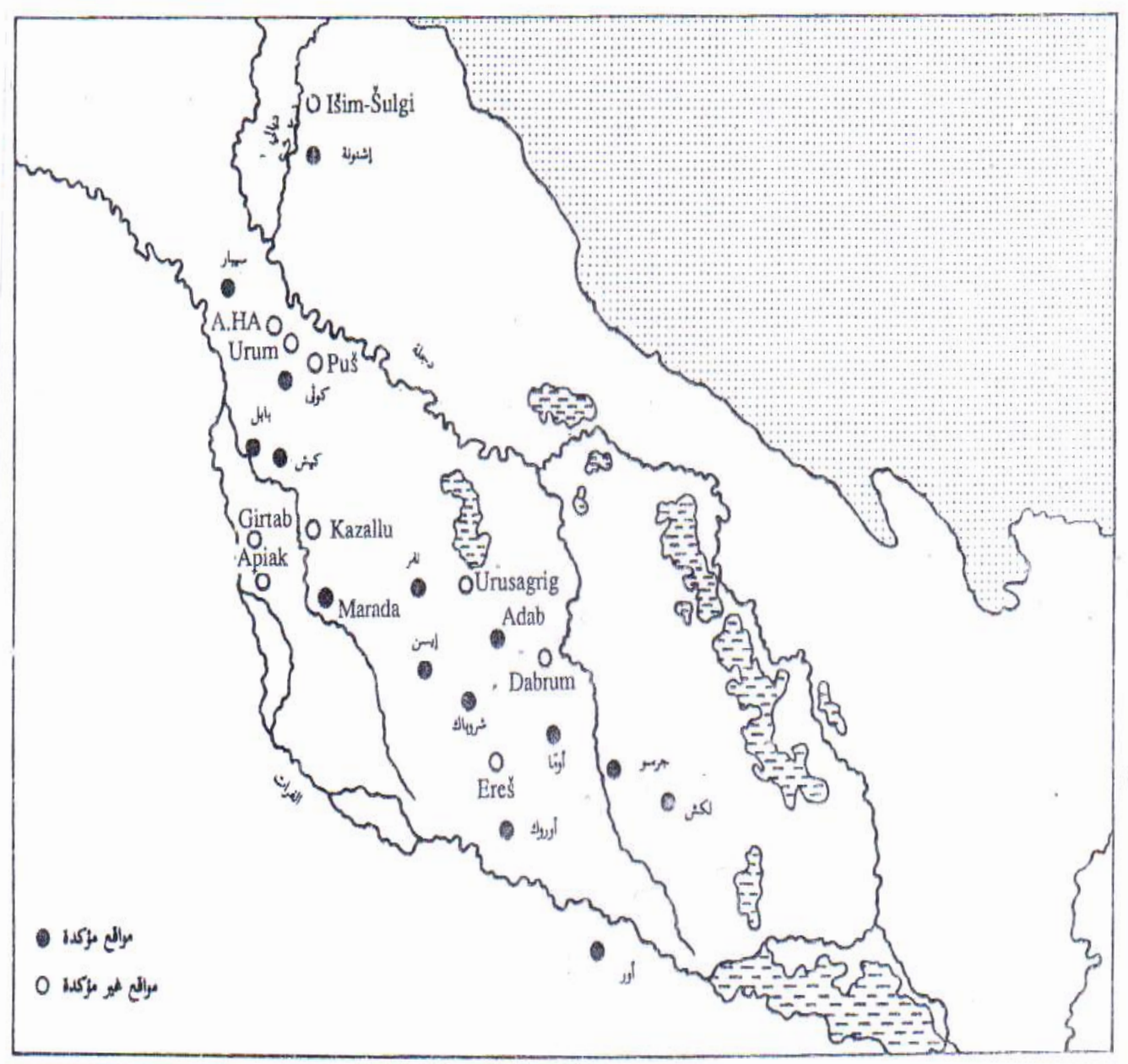

خريطة رقم (1)

خريطة توضح المنطقة المركزية في سومر في عصر أور الثالثة

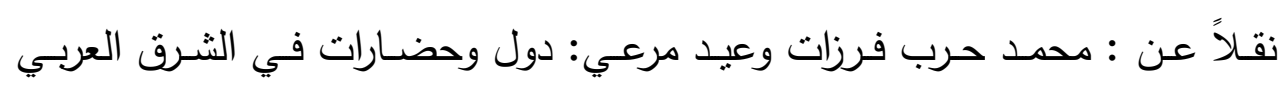

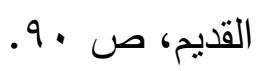




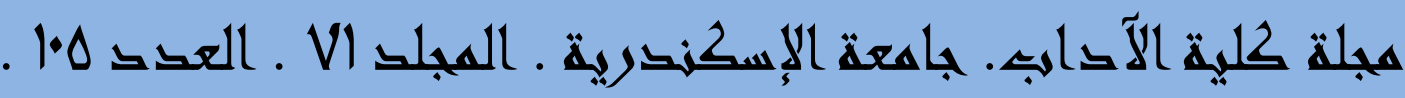

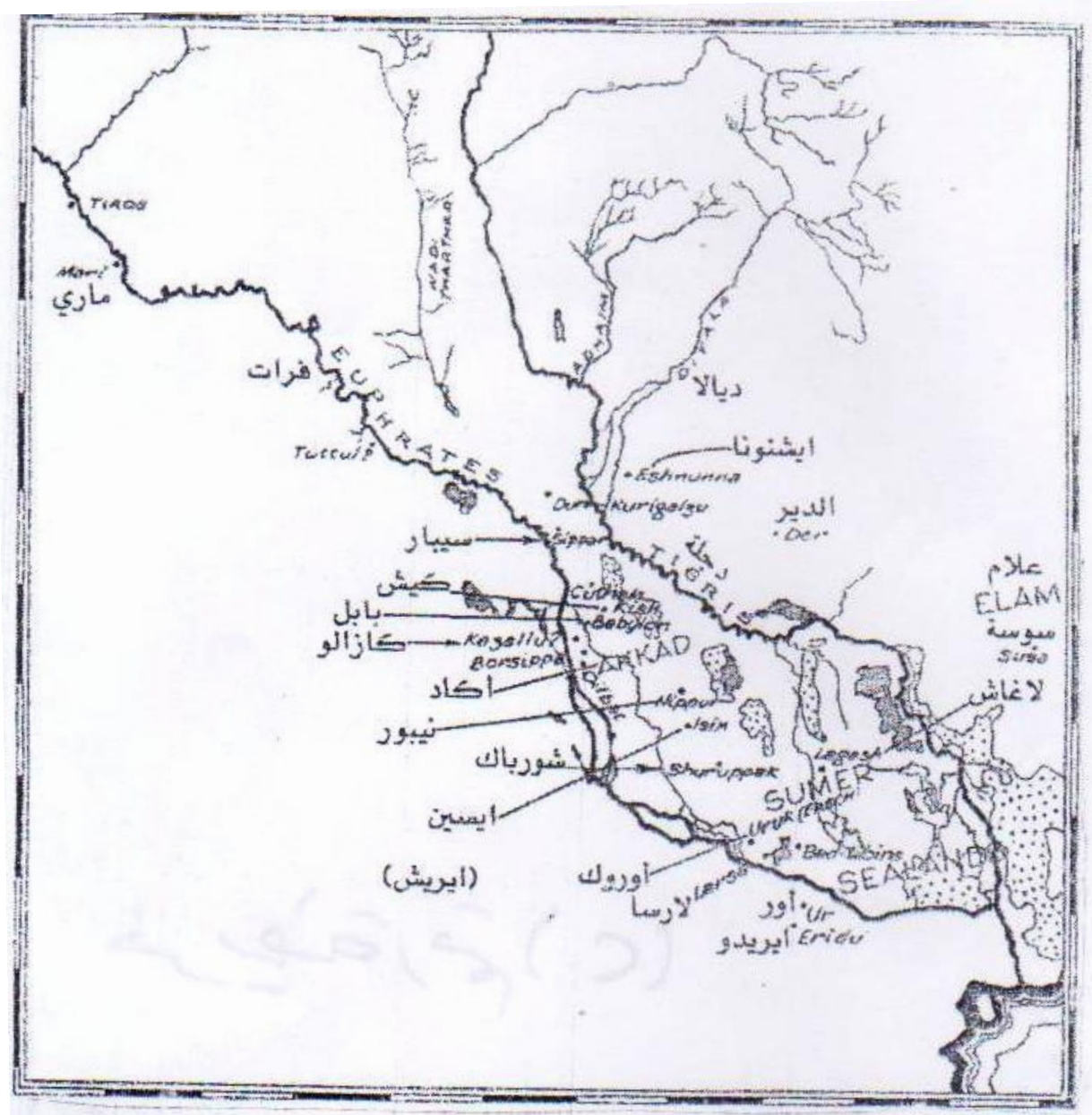

خريطة رقم (r)

خريطة توضح مواقع المدن العراقية في الألف الثاني قبل الميلاد

نقلاً عن: هاري ساغز : عظمة بابل، ص VT. 
ANET : Ancient Near Eastern Texts Relating to the Old Testament, J. B. Pritchard (ed.), Princeton (1969).

CAH : Cambridge Ancient History, Cambridge

CANE : Civilization of Ancient Near East, J. M. Sasson, (and Others, eds.), New York (1995).

IRAN : Journal of Persian Studies, British School of Archaeology in Iran, London.

JAOS : Journal of the American Oriental Society, New Haven.

JCS : Journal of Cuneiform Studies, New Haven.

JNES : Journal of Near Eastern Studies, Chicago.

JRAS : Journal of the Royal Asiatic Society of Great Britain and Ireland, London.

RA : Revue d'Assyriologie et d'Archeaologie Orientale, Press Universities de France. 


\section{قائمة المراجع}

أولاً : المراجعة العربية والمترجمة إلى العربية:

1 - أحمد أمين سليم : دراسات في تاريخ وحضارة الثرق الأدنى القديم (تاريخ

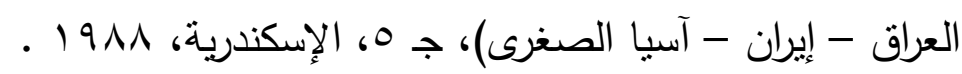

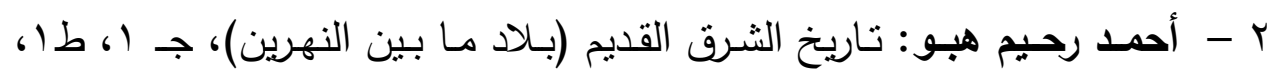
1997. صنعاء، مناء

r - أنطون مورتكات : تاريخ الثرق الأدنى القديم، تعريب: توفيق سليمان وعلي

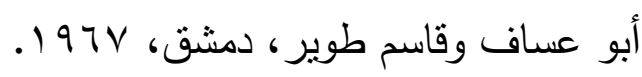

؛ - خزعـل الماجــدي : متـون سـومر (التـاريخ - الميثولوجيـا - اللاهـوت -

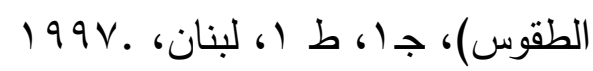

ه - رشــيد الناضــوري : تــاريخ الثـــق الأدنسى القـيم (بـلاد الرافدين وإيـران)،

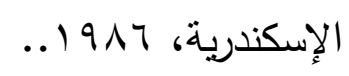

4 - سامي سعيد الأحمد ورضا جواد الهاشعي: تاريخ الثرق الأدنى القديم (إيران

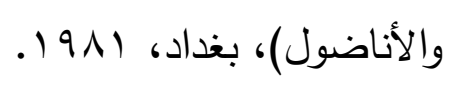

V - سـيتون لويـا : آنار بـلاد الرافدين من العصر الحجري القديم حتى الغزو

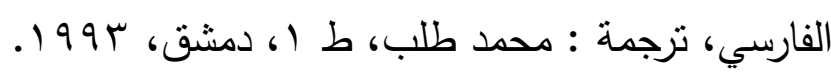

^ - طه باقر : مقدمة في تاريخ الحضارات القديمة، جـ (، بغداد، 9. . . .

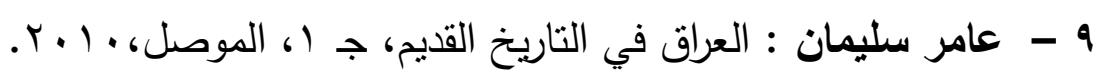

. 1 - عباس علي الحسيني : مملكة إيسن بين الإرث السومري والسيادة الآمورية،

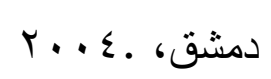

11 - عبد العزيـز صـالح : الثـرق الأدنى القديم (مصر والعراق)، جـ ، طس، .

القاهرة، . 199. 
r ا - عـلاء الـدين شـاهين : حضـارات الثــرق الأدنـى القديم، جـ بـ، القـاهرة، r. . O

r 1 - علي أبو عساف : فنون الممالك القديمة في سورية، دمشق، ب999 1. ؛ 1 - عيد مرعي وفيصل عبد الله : تاريخ الوطن العربي القديم (بلاد الرافدين)،

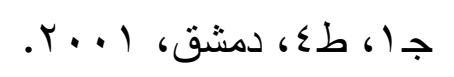

1 - فاضل عبد الواحد علي : صراع السومريين والأكديين مع الأفوام الثرقية

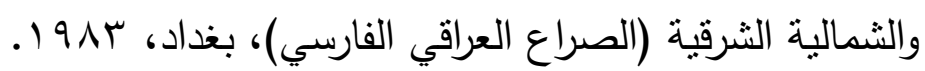
19 - قصسي منصسور التركي : الصـلات الحضـارية بين العراق والخليج العربي

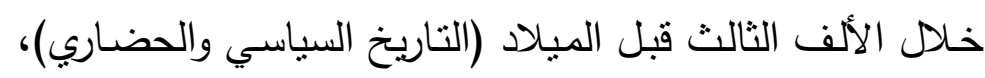

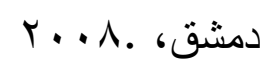

IV - محمد حرب فرزات وعيد مرعي : دول وحضارات في الثرق العربي القديم،

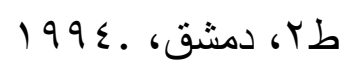

1 1 19VV. محمد عبد اللطيف محمد : تاريخ العراق القديم، جY، الإسكندرية، 19

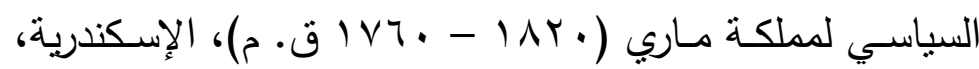
.1910

• • ه - هاري ساغز : عظمة بابل، ترجمة : خالد أسعد عبسي وأحمد غسان سبانو،

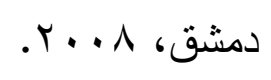

\section{ثانياً : المراجع الأجنبية:}

1. Bottero, J., "Syria befor 2200 B.C.", CAH, Vol. 1, Part 2A, Cambridge (1971). 
2. Charpin, D., "The History of Ancient Mesopotamia: An Overview", C.A.N.E., J. M. Sasson, (and Others, eds.), New York (1995).

3. Covensky, M., The Ancient Near Eastern Tradition, New York and London (1966).

4. Crawford, H., Sumer and the Sumerians, Cambridge (1991).

5. de Boer, R., "Marad in the Early Old Babylonian Period : Its Kings, Chronology, and Isin's Influence", JCS, Vol. 65 (2013).

6. De Mieroop, M. V., "Documents from the Reigns of Išbi Erra and Šu - ilišu", JAOS, Vol. 3, No. 2 (1991).

7. Delaporte, L., Mesopotamia the Babylonian and Assyrian Civilization, Translated by V. G. Child, London and New York (1996).

8. Fitzgerald, M. A., The Rulers of Larsa, Yale University, New Haven (2002).

9. Frayne, D., "Ur III Period (2112 - 2004 B.C.)", JNES, Vol. 63, No. 3 (2004).

10. Gadd, C. J., "Babylonia C. 2120 - 1800 B.C.", CAH, Vol. 1, Part 2A, Cambridge (1971).

11. Gelb, I. J., "The Early History of the West Semitic Peoples, JCS, 15 (1961).

12. Hansman, J., "Elamites, Aghaemenians and Anshan", Iran, Vol. 10 (1972). 
13. Hinz, W., "Persia C. 2400 - 1800 B.C", CAH, Vol. 1, Part 2, London and New York (1971).

14. Jacobsen, T., "The reign of Ibbisuen", JCS, Vol. 7 (1953).

15. Klein, J., "Shulgi of Ur : King of aneo - Sumerian Empire ", CANE, J. M. Sasson, (and Others, eds.), Vol. 2, New York (1995).

16. Kramer, S. N., "A Sumerian Letter", ANET, Princeton (1969).

17. ................., "Sumerian Lamentation", Lamentation over the Destruction of Sumer and Ur, ANET, Princeton (1969).

18. Kubrt, A., the Ancient Near East C. 3000 - 330 B.C., Vol. 1, London and New York (1995).

19. Kupper, J. R., "Un Gouvernement Provincial dans le royaume de Mari", RA, 41 (1947).

20. Langdon, S., "The Location of Isin", JRAS, No. 3 (1922).

21. Liverani, M., The Ancient Near East: History, Society and Economy, London (2013).

22. Macqueen, J. G., Babylon, London (1964).

23. Michalowski, P., "Magan and Meluhha Once Again, JCS, Vol. 40, No. 2 (1988).

24. Oates, J., Babylon, Thames and Hudson, London (1979).

25. Potts, D. t., Ancient Magan, United Arab Emirates (2000).

26. Roux, G., Ancient Iraq, Second edition, Penguin Books, England (1980). 


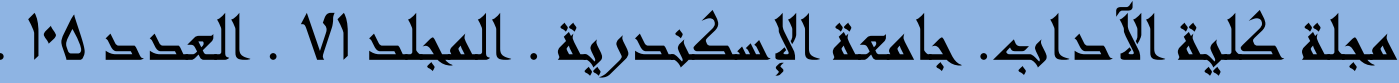

27. Saggs, H. W. F., Everyday Life in Babylonia and Assyria, New York (1965).

28. Sollberger, E., "New Lists of the King of Ur and Isin", JCS, 8 (1954).

29. Stephens, F. J., "New date formulae of the Isin Dynasty", RA, Vol. 33, No. 1 (1936).

30. Woolley, L., Ur of the Chaldees, London (1963). 